\title{
A VIRTUAL WALL OF SHAME: THE NEW WAY OF IMPOSING REPUTATIONAL SANCTIONS ON DEFIANT STATES
}

\author{
SHAI DOTHAN*
}

\begin{abstract}
What happens after an international court finds a state has violated international law? Many realize today that states often fail to comply with such judgments. International courts like the European Court of Human Rights ("ECHR") have to rely on the help of Non-Governmental Organizations ("NGOs") to shame states into compliance. In 2011, the body charged with enforcing judgments of the ECHR launched a new website dedicated to publishing reports by NGOs that criticize states for noncompliance with ECHR judgments. This website published hundreds of reports, as well as the responses of some accused states. The Article analyzes all the reports published in the first four years since the website was created. This analysis, together with interviews with many of the NGO lawyers involved, sheds light on the way reputational sanctions work in international law. It reveals that NGOs focus most of their attention on legally important cases and on cases that address severe violations. It also shows that NGOs focus on states that usually comply with their international obligations instead of on states that regularly fail to comply with international law.
\end{abstract}

Copyright (C) 2017 Shai Dothan

* Associate Professor of International and Public Law (tenured), University of Copenhagen Faculty of Law affiliated with iCourts. PhD, LLM, LLB, Tel Aviv University Faculty of Law. I thank Karen J. Alter, Patrick Barry, Or Bassok, Eyal Benvenisti, Lisa Bernstein, Avinoam Cohen, Yoav Dothan, Federico Fabbrini, Olga Frishman, Rotem Giladi, Tom Ginsburg, Francoise Hampson, Laurence R. Helfer, Saggi Katz, Michal Lavi, Mikael Rask Madsen, Christopher McCrudden, Ioannis Panagis, and Uri Regev for many instructive conversations and comments. I thank participants in the Max Planck Institute for Comparative Public Law and International Law Seminar, the Midwestern Law and Economics Association 2014 Annual Meeting, the University of Chicago Legal Scholarship Workshop, the Northwestern University Legal Scholarship Workshop, the iCourts Research Seminar, the Spanish Law and Economics Association 2015 Annual Meeting, the German Law and Economics Association 2015 Annual Meeting, the European Association of Law and Economics 2015 Annual Meeting, the Trust, Social Capital and Networks Conference, the Practice of Interpretation of European Courts Conference, the ICON-S 2016 Conference, the First Conference on Empirical Legal Studies in Europe, and the Italian Society of Law and Economics Annual Conference. This research is funded by the Danish National Research Foundation Grant no. DNRF105 and conducted under the auspices of iCourts, the Danish National Research Foundation's Centre of Excellence for International Courts. 


\section{TABLE OF CONTENTS}

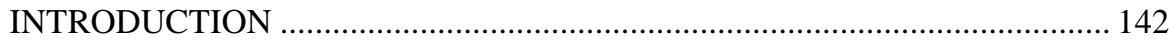

I. THE ECHR AND ITS ENFORCEMENT MECHANISM............................... 145

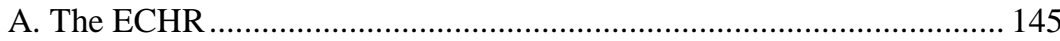

B. The Committee of Ministers.......................................................... 147

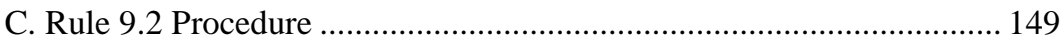

II. WHICH TYPES OF JUDGMENTS ATTRACT THE MOST NGO

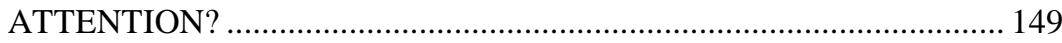

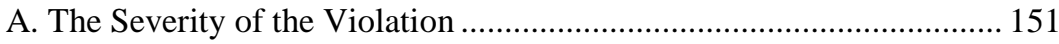

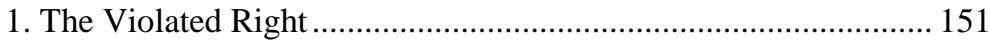

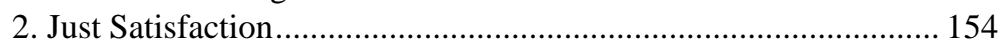

B. The Legal Importance of the Case ...................................................... 155

1. HUDOC Categorization ……………………………….............. 155

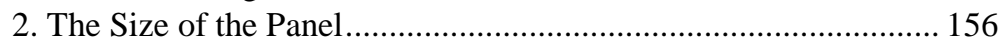

3. Judicial Dialogue....................................................................... 157

4. Other Proxies for Salience............................................................ 157

C. Conclusions on the Focus of NGO Attention ..................................... 159

III. WHICH TYPE OF STATES DRAW THE MOST NGO ATTENTION?..... 159

A. Measuring States' Reputation ........................................................... 159

B. The Connection Between State Reputation and NGO Applications.... 162

C. Alternative Explanations For the Focus of NGOs on High-Reputation

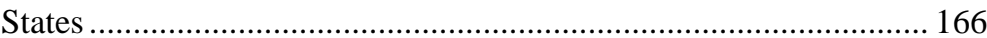

1. Willingness to Reply to NGO Reports ............................................ 166

2. Willingness to Cooperate with the Committee of Ministers ........ 167

3. Willingness to Comply with Judgments ......................................... 168

4. NGO Past Involvement …………………………………......... 169

5. A Concentration of Severe and Important Violations in HighReputation States 171

D. Conclusions about the Focus of NGOs on High-Reputation States .... 173

IV. WHAT DO NGOS REALLY WANT? ………………………………........ 173

A. Separating NGOs According to Size .................................................. 174

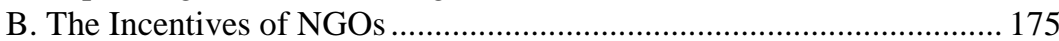

V. IMPROVING REPUTATIONAL ASSESSMENTS ...................................... 179

A. Imperfect Information Makes Every Deed Count ................................. 180

B. Opening the Shaming Community to Prevent Echo ………………...... 182

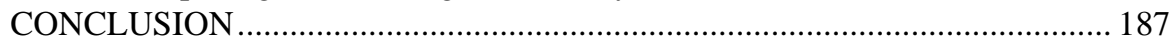

\section{INTRODUCTION}

The Committee of Ministers of the Council of Europe ("CM") is the body charged with enforcing judgments of the European Court of Human Rights ("ECHR"). Although the CM is theoretically able to expel a state from the Council of Europe, it has never done so and cannot credibly threaten 
to use this extreme step. To convince states to comply with ECHR judgments, the CM must rely on publicly shaming the states by exposing their defiant behavior in its discussions and in public documents it releases, which are known as "interim resolutions." As the number of disobeyed judgments increased, the CM was pushed to devise a new strategy to make states comply.

This strategy was the creation in 2011 of a website dedicated to publishing reports ${ }^{1}$ by Non-Governmental Organizations ("NGOs"). The

1. It is important to stress that NGOs began filing reports long before the DEJ website was created; they have been filing since May 2006 when Rule 9 was amended and allowed them to intervene. Yet these reports were not transparent and accessible to the public unless NGOs deliberately published them on their own websites or in publications. See, e.g., RUSSIAN JUSTICE INITIATIVE, IMPLEMENTATION RESOURCES AND MATERIALS, http://www.srji.org/en/implementation/materials/ [https://perma.cc/G7HB -TE4Y]. Reports that do not appear on the DEJ website are excluded from the analysis here.

All reports were downloaded from the Council of Europe online database. Council of Europe, Latest Documents, http://www.coe.int/en/web/cm/latest-documents [https://perma.cc/X7ES-N88D] (reports originally accessed on Dec. 42014 from the previous version of this website, http://www.coe.int/t/cm/System/WCDsearch.asp?ShowRes=yes\&FilingPlan=fplCM-Supervision9_2\& Language $=$ lanEnglish $\&$ ShowBreak $=$ es $\&$ SortBy $=$ Geo $\&$ Sector $=$ secCM $\&$ ShowFullTextSearch $=$ yes $\&$ ResultTitle=Information $\% 20$ from $\% 20$ NGOs $\% 20$ and $\% 20$ National $\% 20$ human $\% 20$ rights $\% 20$ institutions). This database keeps reports also on judgments that were closed by the CM, including some of the cases analyzed here. In addition, on Oct. 31, 2013, all reports were downloaded from another part of the website, which contains all communications received on pending cases: http://www.coe.int/t/dghl/monito ring/execution/Themes/Add_info/Info_cases_en.asp [https://perma.cc/MQT5-VUHQ]. While cases could be closed and would not appear on the second website, as were some cases in the sample, they continue to appear on the first, specialized website that should contain all reports. Yet, some reports are missing from the first website, although they appeared on the second website. These were included in my sample to give the most accurate picture of the reports actually filed and accessible on at least one CM website. Almost all of them are reports issued in the infancy of the website in 2010 or 2011 and may have been unintentionally omitted from the specialized first website. The number of these missing reports are (2010)410, (2010)407, (2010)398, (2011)698, (2010)336, (2011)298, (2011)680, (2013)380, (2011)787, (2010)610. All ten reports concern cases that were still pending on Jan. 28, 2015.

Another oddity worth mentioning are three reports dating from 2007-2008 against France that were later published in the first website although they were clearly filed long before the website was created together with many other cases that were never published. These reports are (2007)600, (2007)531, (2008)119, which all address the same case: app. no. 25389/05 Gaberamadhien v. France. Even an official at ANAFE, the organization that filed the three reports, could not tell why they were published so late after they were filed while similar reports were not. See Conversation with Official at ANAFE (Association nationale d'assistance aux frontières pour les étrangers) on 27/5/15. These reports were included in the database to give the most accurate picture of the CM website.

All information about the current status of the cases in the $\mathrm{CM}$ and communications filed regarding them was coded or updated in December 2014 and January 2015. This information was collected from queries at http://www.coe.int/t/dghl/monitoring/execution/Reports/pendingCases_en.asp and from data on resolutions and documents filed taken from other places in the CM's website.

The CM now has a new and elegant website at http://www.coe.int/cs/web/execution/submissions. One can find there information about submissions by states, applicants, NGOs, and national human rights institutions (NHRIs) categorized by the relevant state. One can access specifically information submitted by NGOs and NHRIs at https://search.coe.int/cm\#title=Information $\% 20$ from $\% 20 \mathrm{NGOs} \% 20 \mathrm{and} \% 20$ nati onal\%20human\%20rights\%20institutions\#showSearchBar=static\#k=*\#f=\%5B\%7B \%22p\%22\%3A\%22 
reports accuse states of failing to fully comply with judgments of the ECHR. They are published promptly, together with any response from the state accused of non-compliance. In this way, hundreds of organizations can participate in exposing the non-compliant actions of states. NGOs can learn about state behavior from each other, add their own observations in new reports, and spread this information further in their publications.

From the creation of the website until December 2014, 266 NGO reports were published, targeting compliance with 137 ECHR judgments. This Article analyzes all these reports, along with information from interviews with NGO activists who submitted them. The Article suggests that NGOs focus mainly on cases of significant legal importance and on issues that concern severe human rights violations. Furthermore, NGOs focus on states that are usually compliant with international law-so-called "high-reputation states."

These findings shed light on the way reputational sanctions work in international law. Apparently, allowing numerous NGOs that are very different from each other to use shaming sanctions can help focus most of the attention on the cases that matter the most legally and morally. Moreover, states that have built a high reputation through years of good behavior are shamed more often than regularly misbehaving states. The reason for this seems to be that states which acquired a good reputation have more to lose from accusations of inadequate behavior. They are, therefore, more likely to improve their behavior if their noncompliance is exposed. This, in turn, gives NGOs an incentive to target these high-reputation states instead of wasting efforts on states that do not care much about their reputation.

Scholars have noted that once an international court issues a judgment, state compliance is not guaranteed. In fact, compliance can be partial or delayed. ${ }^{2}$ This Article adds to this literature. It joins those scholars who argue that the level of state compliance often depends on the actions of individuals and organizations interacting with the government of that state. ${ }^{3}$ NGOs play

CoEFilter $\% 22 \% 2 \mathrm{C} \% 22 \mathrm{i} \% 22 \% 3 \mathrm{~A} 1 \% 2 \mathrm{C} \% 22 \mathrm{o} \% 22 \% 3 \mathrm{~A} 1 \% 2 \mathrm{C} \% 22 \mathrm{~m} \% 22 \% 3 \mathrm{~A} 0 \% 2 \mathrm{C} \% 22 \mathrm{ix} \% 22 \% 3 \mathrm{~A} 1$ $\% 2 \mathrm{C} \% 22$ value $\% 22 \% 3 \mathrm{~A} \% 22$ Information $\% 20$ from $\% 20$ NGOs $\% 20 \% 26 \% 20$ National $\% 20 \mathrm{HR} \% 20$ instituti ons\%20(Rule\%209.2)\%22\%7D\%5D [https://perma.cc/QTZ6-48MQ].

2. See Alexandra Huneeus, Compliance with Judgments and Decisions, in THE OXFORD HANDBOOK OF INTERNATIONAL ADJUDICATION 437, 443-45 (Cesare P. R. Romano, Karen J. Alter, \& Yuval Shany eds., 2013) (explaining the difficulties of measuring state compliance with international judgments and referring to empirical studies of compliance); YUVAL SHANY, ASSESSING THE EFFECTIVENESS OF INTERNATIONAL COURTS 120-23 (2014) (studying the factors that affect compliance with international judgments).

3. See Courtney Hillebrecht, Domestic Politics and International Human Rights TRIBUNALS: THE PROBLEM OF COMPLIANCE 135 (2014) (arguing that domestic actors are essential for securing compliance with human rights judgments of international courts). 
an important role in this regard, ${ }^{4}$ but they are constrained by their limited abilities $^{5}$ and their intervention does not necessarily have a positive effect. ${ }^{6}$ Therefore, to fulfill its goal of enforcing ECHR judgments, the CM must be sensitive to the complex reality unfolded in this Article. ${ }^{7}$

Part I describes the ECHR and the CM, with special emphasis on the new website where NGOs can publish reports on states' noncompliance. Part II shows which types of judgments attract the most NGO attention. Part III presents the type of states that are the subject of increased NGO attention. Part IV offers data about the NGOs involved in filing reports, including insights from a series of interviews with NGO activists. Part V explores potential reasons for inaccuracies in the way the international community perceives states' reputations and suggests that the involvement of NGOs may improve the community's reputational assessments. Part VI concludes by highlighting how the Article's findings lend empirical support to a key argument made in the literature on reputation - that high-reputation states stand to lose more than low-reputation states when targeted by a reputational sanction.

\section{THE ECHR AND ITS ENFORCEMENT MECHANISM}

\section{A. The ECHR}

The ECHR is an international human rights court located in Strasbourg, France. It has jurisdiction over violations of the Convention for the Protection of Human Rights and Fundamental Freedoms ${ }^{8}$ (the "Convention") committed by the forty-seven member states comprising the Council of Europe. The Convention protects key human rights such as the right to life and the right to freedom from torture, ${ }^{9}$ as well as numerous other

4. See id. at 24 (arguing that NGOs can pressure governments and shame them into compliance with international judgments).

5. See Kenneth Roth, Defending Economic, Social and Cultural Rights: Practical Issues Faced by an International Human Rights Organization, 26 HUM. RTS. Q. 63, 67-68 (2004) (asserting that shaming by NGOs is effective mainly when the violation, the identity of the violator, and the necessary remedy are clear).

6. See Emilie M. Hafner-Burton, Sticks and Stones: Naming and Shaming the Human Rights Enforcement Problem, 62 INT'L ORG. 689, 707 (2008) (showing that countries which are shamed for human rights abuses often improve their protection of political rights; however, shaming sometimes leads to increased political terror).

7. See Başak Çali \& Anne Koch, Foxes Guarding the Foxes? The Peer Review of Human Rights Judgments by the Committee of Ministers of the Council of Europe, 14 HUM. RTS. L. REV. 301, 324 (2014) (suggesting that CM procedures improve the prospects of compliance with ECHR judgments).

8. Convention for the Protection of Human Rights and Fundamental Freedoms, Nov. 4, 1950, 213 U.N.T.S. 222, as amended by Protocols No. 3 (Sept. 21, 1970), 5 (Dec. 20, 1971), 8 (Jan. 1, 1990), 11 (Nov. 1, 1998), and 14 (June 1, 2010) [hereinafter The Convention].

9. Id. at arts. 2 and 3 , respectively. 
rights such as the right to a fair trial, to privacy, and to freedom of religion. ${ }^{10}$ The Convention also requires states to provide effective remedies for any violation and not to discriminate between individuals. ${ }^{11}$

Individuals, groups, and NGOs can bring cases to the ECHR as applicants if they were victims of violations. ${ }^{12}$ States can also bring cases against other states even if they were not victims of violations, ${ }^{13}$ but they rarely do so. ${ }^{14}$ The ECHR employs forty-seven permanent judges-one judge for each state in the Council of Europe. ${ }^{15}$ The court sits in panels of various sizes: single-judge Formations, Committees of three judges, Chambers of seven judges and a Grand Chamber of seventeen judges. ${ }^{16}$ Most of the ECHR's significant cases are issued by Chambers, with the Grand Chamber reserved only for issues of extreme legal importance. ${ }^{17}$

Over the years, the number of cases reaching the ECHR has skyrocketed. While the court received 45,000 cases in the first forty-three years of its existence, ${ }^{18}$ in 2013 alone it received more than 65,000 cases. ${ }^{19}$ To address this flood of cases, the ECHR has undergone several reforms. In 1998, the commission previously responsible for screening cases before they reached the ECHR was abolished, ${ }^{20}$ and in 2010 , single-judge Formations

10. Id. at arts. 6, 8, and 9, respectively.

11. Id. at arts. 13 and 14 , respectively.

12. Id. at art. 34 .

13. Id. at art. 33.

14. See Dragoljub Popovic, Prevailing of Judicial Activism over Self-Restraint in the Jurisprudence of the European Court of Human Rights, 42 CREIGHTON L. REV. 361, 372 (2009) (arguing that more than ninety-five percent of the cases brought before the court were not applications by states).

15. Every state in the Council of Europe can suggest a list of three candidates to the parliamentary assembly from which the assembly selects one judge. See The Convention, supra note 8, at arts. 20, 22.

16. The Convention, supra note 8 , at art. 27.

17. A Chamber that received a case may decide to pass the case to a Grand Chamber if it finds the case raises a serious question of interpretation, or if the case might lead to a digression from prior judgments. If the Chamber issues a judgment, it does not become immediately final. Within three months after the Chamber judgment, a party to the dispute can, in exceptional cases, ask for a referral to the Grand Chamber. A panel of five judges will allow the case to be heard again by a Grand Chamber if the case raises a significant issue of interpretation or an issue of great importance. If three months have passed since the Chamber judgment and neither party has requested a referral, if both parties have declared they do not wish to refer the case, or if the court has decided to reject a referral request, the Chamber judgment will become final. See The Convention, supra note 8, at arts. 30-31, 42-44.

18. From 1955 to 1998 , 45,000 applications were allocated to judicial formations. See EUR. CT. H.R., ANNUAL REPORT 200911 (2009), http://www.echr.coe.int/NR/rdonlyres/C25277F5-BCAE-4401BC9B-F58D015E4D54/0/2009_Annual_Report_Final.pdf [https://perma.cc/6VKM-QLFR].

19. In 2013, 65,900 applications were allocated to judicial formations. See EuR. CT. H.R., ANALYSIS OF STATISTICS 20134 (Jan. 2014), http://www.echr.coe.int/Documents/Stats_analysis_2013_ ENG.pdf [https://perma.cc/6DZK-QW5K].

20. In Protocol 11, which was accepted on November 1, 1998. 
were authorized to reject plainly inadmissible cases. ${ }^{21}$ Consequently, the ECHR processes an increasingly large volume of cases. In 2013, it disposed of more than 93,000 cases, reducing the court's accumulated backlog to slightly less than $100,000 .^{22}$

ECHR judgments finding states in violation of the Convention are legally binding. States must comply with these judgments by choosing the appropriate means to remedy the violation. ${ }^{23}$ These means can range from specific measures such as releasing prisoners to general measures such as amending statutes. $^{24}$ If parties harmed by violations have not been compensated by the state's domestic laws, the ECHR can grant them "just satisfaction," which are reparations to cover their harms.

The ECHR cannot enforce its judgments. This task is left entirely to the CM. Though some scholars argue that states regularly comply with ECHR judgments, ${ }^{25}$ many are concerned that a large number of the cases reaching the court are in fact repetitive cases - cases arising from structural defects that were not resolved and continue to harm numerous applicants. To better address these structural defects, the court occasionally issues so-called "pilot judgments"- judgments that prescribe specific actions to remedy the violation. $^{26}$

\section{B. The Committee of Ministers}

The CM monitors compliance with the ECHR's judgments together with the Department of Execution of Judgments ("DEJ"). ${ }^{27}$ These bodies are charged with supervising both the individual measures necessary to amend a violation vis-à-vis the applicant, including the payment of just satisfaction, and the general measures necessary to prevent similar violations, such as constitutional or statutory amendments. Theoretically, the CM can expel states from the Council of Europe, but this severe measure has never been

21. In Protocol 14, which came into force on June 1, 2010. Protocol 14 also allows three-judge Committees to declare admissible and decide on the merits cases that are clearly well-founded. Furthermore, the Protocol allows the court to declare cases inadmissible if they create no significant disadvantage to the applicant and do not raise an important legal question.

22. In 2013, 93,396 applications were processed. This reduced the court's backlog from 128,100 cases at the beginning of the year to 99,900 cases at its end. See ANALYSIS OF STATISTICs 2013, supra note 19 , at 4 .

23. The Convention, supra note 8 , at art. 46.

24. See Scozzari and Guinta v. Italy [GC], 2000-VIII Eur. Ct. H.R. 471.

25. See Shai Dothan, Judicial Tactics in the European Court of Human Rights, 12 CHI. J. INT'L L. 115,119 (2011) (presenting the research on compliance rates with the ECHR and arguing that by most accounts compliance rates are high).

26. See Broniowski v. Poland [GC], 2004-V Eur. Ct. H.R. 1.

27. The Convention, supra note 8 , at art. 46(2). 
used. ${ }^{28}$ In practice, the CM therefore limits itself to spreading information and shaming states into compliance.

After a final judgment is issued against a state, the DEJ begins to negotiate with the state about how to remedy the violation. After this initial stage, which should last no more than six months, the state is required to submit an "action report." The report describes the measures the state took to comply and a timeline for the measures it intends to take. If a state does not comply quickly enough, the CM may examine its actions regularly and request that the state act in certain ways. If the state continues to delay compliance, the CM may issue a public proclamation called "interim resolution" condemning the state for noncompliance and urging it to change its practices. $^{29}$

The CM divides its efforts of supervision into two separate tracks. Most cases are directed to the track called "standard procedure." Some cases that need closer attention, such as cases that require urgent action or involve severe structural problems, are directed to the "enhanced procedure" track. Cases supervised under this "enhanced procedure" are regularly raised in the CM meetings. ${ }^{30}$

The CM categorizes cases that deal with general wide-spread problems - and consequently require general measures of remediation - as "Leading Cases." 31 The CM supervises compliance with a Leading Case together with the repetitive cases that result from the same violation.

In 2011, the DEJ created a website that publishes all the information about states' compliance, including action reports submitted by the states and interim resolutions issued against them. This new source of information allows civil society to monitor states' compliance behavior and shape states' reputations.

28. See Statute of the Council of Europe, art. 8, 5 May 1949, 87 U.N.T.S. 103 (stating that the CM may suspend the representation rights of states that violate their commitment to the Council of Europe or even expel such states from the Council). While no state has been expelled under this provision, Greece withdrew from the Council of Europe in 1969 under a possible threat of expulsion. See Dothan, supra note 25 , at 119,139 .

29. Lucja Miara \& Victoria Prais, The Role of Civil Society in the Execution of Judgments of the European Court of Human Rights, 5 EuR. HuM. RTS. L. REV. 528, 531 (2012).

30. If the most crucial elements of compliance are completed, such cases might be downgraded to "standard procedure." In contrast, in cases of persistent noncompliance, a case might be upgraded from "standard procedure" to "enhanced procedure." See id. at 532.

31. Council of Europe, 7TH AnN. ReP. OF the Comm. Of Ministers 33 (2013). 


\section{Rule 9.2 Procedure}

Rule 9.2 of the CM Rules allows the CM to consider communications from NGOs and national institutions for the protection of human rights. ${ }^{32}$ Thus, NGOs are not only passive recipients of information. Rather, they can share their own views about states' compliance with the CM. The NGO reports are sent to the state, which is given five days to respond to them if it wishes. After five days, both the report and the state's response, if there was any, are promptly published on the DEJ's website. ${ }^{33}$

The reports in the database analyzed in this Article were filed by over two hundred NGOs of diverse characteristics and backgrounds. Surprisingly, large and well-funded organizations such as Amnesty or Human Rights Watch were responsible only for a few of the reports in the database. ${ }^{34}$ In contrast, some reports were filed by organizations that are as specialized as the Association of Pensioners of the Republic of Srpska. ${ }^{35}$

Many times, several NGOs participated in filing the same report, or in filing several reports regarding the same judgment. While many judgments drew reports from a single $\mathrm{NGO}^{36}$ in one instance as many as fifty-five NGOs were involved in filing reports regarding a single judgment. ${ }^{37}$

\section{WHICH TYPES OF JUDGMENTS ATTRACT THE MOST NGO ATTENTION?}

The reputation of states reflects the beliefs of the international community about their practices. These beliefs evolve based on accusations targeting the states by foreign governments, courts, and other actors such as NGOs. The DEJ website is only one arena where states are publicly shamed for their practices. Nevertheless, much can be learned about the incentives and strategy of NGOs from how they use this arena. The strategy NGOs employ may carry through to other arenas as well, such as their own media publications and their discussions.

In order to decipher how NGOs divide their attention, two methods of analyzing the relevant data are used. The first method compares the 137 cases that led to NGO reports to the "general population" of cases - a sample

32. Committee of Ministers, ApPendix 4: Rules of the COMmitTeE of Ministers for the SUPERVISION OF THE EXECUTION OF JUDGMENTS AND OF THE TERMS OF FRIENDLY SETTLEMENT, RULE 9.2 (2006).

33. Lucja Miara \& Victoria Prais, supra note 29, at 534, 536.

34. For further analysis, see infra Part II.A.

35. See Karanovic v. Bosnia and Herzegovina, App. No. 39462/03, 2008 Eur. Ct. H.R. (Fourth Section), not reported.

36. For additional detail, see infra Part II.

37. Fatullayev v. Azerbaijan, App. No. 40984/07, 2010 Eur. Ct. H.R. (First Section) (unpublished). 
consisting of all the Chamber and Grand Chamber Judgments ${ }^{38}$ issued in English $^{39}$ from January 1, 2008 ${ }^{40}$ to October 31, $2013^{41}$ in which the ECHR found at least one violation and which are not part of the group of cases that led to NGO reports. In this sample, the court found 7,847 violations ${ }^{42}$ in a total of 5,584 judgments. Comparing the judgments that led to NGO reports with the judgments from the general population will help determine if NGOs tend to file reports especially on issues of a certain type.

The second method sorts cases that led to NGO reports according to the amount of attention they received. This method relies on three proxies for special NGO attention: the number of reports filed, ${ }^{43}$ the number of NGOs

38. The first method employed involved a comparison between the number of cases that did lead to NGO reports and the number of cases that did not lead to NGO reports. The latter number is the total sample size of cases described less the cases that led to NGO reports. Only one $(0.73 \%)$ of the cases that led to NGO reports was issued by a court committee. Since committee judgments typically accompany more technical cases that have become common only in recent years due to structural changes initiated by Protocol 14, they were excluded from the group.

39. While some judgments do not have a full English language version on HUDOC, all judgments have their case details coded in English as well. These details appear when English documents are searched, assuring that all the judgments issued by the ECHR at this period are represented in the sample.

40. Of the 137 cases that led to NGO reports, only thirty-four judgments became final (Grand Chamber judgments are final immediately, Chamber judgments become final three months after they are issued if no referral to the Grand Chamber was requested; see art. 44 to the Convention) before Jan. 1, 2008, with the earliest becoming final on Oct. 30, 1998. The Oct. 30, 1998 judgment is the only judgment that became final before Protocol 11 came into force on Nov. 1, 1998. Only nine cases became final before Jan. 1, 2005. Although the number of applications filed per year increased rapidly between Nov. 1998 and 2008, there was no procedural change in the court at this period and no reason to believe that older judgments, especially the judgments issued only a couple of years before 2008, differ systematically from judgments in the general population.

41. All 137 cases that led to NGO reports became final before Oct. 31, 2013. The most recent case became final on Oct. 21, 2013.

42. According to a HUDOC coding of violations of articles mentioned in Table 1 of this Article. Many judgments contain more than one violation. In my data and in the HUDOC database, several violations of the same article in the same judgment are counted as one violation.

43. There are large differences in the amount of attention NGOs devoted to judgments, even when they did file a report: $67.15 \%$ of the judgments that led to NGO reports led to only 1 NGO report; $24.82 \%$ led to 2-4 NGO reports; $5.11 \%$ led to 5-10 NGO reports; and only $2.92 \%$ led to 11 or more NGO reports. Some reports involved several NGOs and often the same NGO submitted many reports. In total, 92 of the judgments led to only 1 NGO report, 34 judgments led to 2-4 NGO reports, 7 judgments led to 5-10 NGO reports, and 4 judgments led to 11 or more NGO reports. A few unique cases attracted the extreme attention of NGOs. For example, D.H. and others v. the Czech Republic, App. No. 57325/00, is the only case issued against the Czech Republic that led to NGO reports and yet it attracted no less than seventeen reports involving ten different NGOs. The case also attracted a report by the Public Defender of Rightsa national human rights institution. Just as unique is the fact that nine NGOs participated as third parties in the application itself, yet none of them are included in the group of NGOs that filed a report later on. In addition, sometimes one NGO report addresses several judgments. To make the coding consistent, only judgments mentioned in the formal title page of the report were coded. Usually the title page covers all judgments actually addressed by the report, but in rare cases (for example, Report (2011)250 filed against Bulgaria) the report itself mentions other judgments likely considered less important or less relevant by the DEJ. 
involved, ${ }^{44}$ and the number of pages contained in all NGO reports. ${ }^{45}$ The Article compares the fifty-four cases that led to "minimal" NGO attentiononly one report, filed by only one NGO, and holding no more than ten pages - with the thirty-eight cases that drew "special" NGO attention-two or more reports, filed by two or more NGOs, and holding at least eleven pages. This comparison can reveal what issues NGOs focus on.

\section{A. The Severity of the Violation}

\section{The Violated Right}

One proxy for the severity of the violation is the type of right that was infringed. Comparing the types of rights that were infringed in the general population of cases and in the cases that led to NGO reports will reveal whether NGOs submit reports on compliance with cases that found severe violations or minor violations.

Table 1 shows the percentage of violations (the number of violations found divided by the number of judgments) in the general population of judgments and in the judgments that led to NGO reports.

Table 1: The Severity of Violations in the General Population and in Cases that Led to NGO Reports

\begin{tabular}{|l|c|c|}
\hline \hline & $\begin{array}{l}\text { Judgments In } \\
\text { the General } \\
\text { Population }\end{array}$ & $\begin{array}{l}\text { Judgments Leading to } \\
\text { NGO Reports }\end{array}$ \\
\hline Article 2 - right to life & $\mathbf{6 . 6 4 \%}$ & $\mathbf{1 3 . 1 4 \%}$ \\
\hline Article 3 - prohibition of torture & $\mathbf{1 8 . 4 8 \%}$ & $\mathbf{2 7 . 7 4 \%}$ \\
\hline $\begin{array}{l}\text { Article 4 - prohibition of slavery and } \\
\text { forced labor }\end{array}$ & $0.05 \%$ & $0.73 \%$ \\
\hline Article 5 - right to liberty and security & $17.37 \%$ & $13.87 \%$ \\
\hline
\end{tabular}

44. The number of NGOs involved in applications regarding a specific case also varies greatly: $60.58 \%$ of the judgments led to applications involving only 1 NGO; $27.01 \%$ led to $2-3$ NGOs involved; $6.57 \%$ led to 4-6 NGOs involved; $5.11 \%$ led to $7-10$ NGOs involved; and another $0.73 \%$ led to 11 or more NGOs involved. In total, 83 judgments led to applications involving only 1 NGO, 37 judgments led to 2-3 NGOs involved, 9 judgments led to 4-6 NGOs involved, and 7 judgments led to 7-10 NGOs involved. Only 1 judgment led to 11 or more NGOs involved.

45. There are also great differences in the length of the NGO reports submitted. Often NGOs attach appendices to their reports including detailed factual backgrounds. Reports range from short letters to detailed documents totaling dozens of pages: $4.38 \%$ of the judgments led to NGO reports totaling 3 pages or less; $43.07 \%$ led to reports totaling between 4 and 10 pages; $17.52 \%$ led to reports totaling between 11 and 20 pages; $21.17 \%$ led to reports between 21 and 50 pages; and $13.87 \%$ led to reports as long or longer than 51 pages (all figures include the introduction page attached by the Department of Enforcement of Judgments and the response of the state, if there was one). In total, 6 judgments led to NGO reports totaling 3 pages or less; 59 judgments led to reports totaling between 4 and 10 pages; 24 judgments led to reports totaling between 11 and 20 pages; 29 judgments led to reports between 21 and 50 pages in length; and 19 judgments led to reports as long or longer than 51 pages. 


\begin{tabular}{|c|c|c|}
\hline Article 6 - right to a fair trial & $54.15 \%$ & $27.74 \%$ \\
\hline Article 7 - no punishment without law & $0.39 \%$ & $0.73 \%$ \\
\hline $\begin{array}{l}\text { Article } 8 \text { - right to respect for private } \\
\text { and family life }\end{array}$ & $8.72 \%$ & $16.06 \%$ \\
\hline $\begin{array}{l}\text { Article } 9 \text { - freedom of thought, } \\
\text { conscience and religion }\end{array}$ & $0.56 \%$ & $6.57 \%$ \\
\hline Article 10 - freedom of expression & $4.14 \%$ & $7.30 \%$ \\
\hline $\begin{array}{l}\text { Article } 11 \text { - freedom of assembly and } \\
\text { association }\end{array}$ & $1.34 \%$ & $7.30 \%$ \\
\hline Article 12 - right to marry & $0.07 \%$ & $0 \%$ \\
\hline $\begin{array}{l}\text { Article } 13 \text { - right to an effective } \\
\text { remedy }\end{array}$ & $12.23 \%$ & $20.44 \%$ \\
\hline $\begin{array}{l}\text { Article } 14 \text { - prohibition of } \\
\text { discrimination }\end{array}$ & $2.01 \%$ & $13.14 \%$ \\
\hline $\begin{array}{l}\text { Protocol } 1 \text { Article } 1 \text { - protection of } \\
\text { property }\end{array}$ & $13.75 \%$ & $11.68 \%$ \\
\hline Protocol 1 Article 2 - right to education & $0.11 \%$ & $5.84 \%$ \\
\hline $\begin{array}{l}\text { Protocol } 1 \text { Article } 3 \text { - right to free } \\
\text { elections }\end{array}$ & $0.14 \%$ & $4.38 \%$ \\
\hline $\begin{array}{l}\text { Protocol } 4 \text { - additional freedoms (of } \\
\text { movements, aliens, etc.) }\end{array}$ & $0.18 \%$ & $2.19 \%$ \\
\hline $\begin{array}{l}\text { Protocol } 6 \text { - abolition of the death } \\
\text { penalty }\end{array}$ & $0 \%$ & $0 \%$ \\
\hline $\begin{array}{l}\text { Protocol } 7 \text { - additional rights (for } \\
\text { appeals, aliens, etc.) }\end{array}$ & $0.18 \%$ & $2.19 \%$ \\
\hline Protocol 12 - general right to equality & $0 \%$ & $0.73 \%$ \\
\hline $\begin{array}{l}\text { Protocol } 13 \text { - complete abolition of the } \\
\text { death penalty }\end{array}$ & $0 \%$ & $0 \%$ \\
\hline Total Percentages & $140.51 \%$ & $181.77 \%$ \\
\hline
\end{tabular}

Table 1 highlights several striking differences. Some of these differences (bolded) may reveal that NGOs tend to focus on violations of special severity according to the Convention article involved. A Two-Tailed Fisher's Exact Test was used to establish the statistical significance of these differences. The same test was used throughout this Article. ${ }^{46}$ Most importantly, there are more violations of Article 2 protecting the right to life in the group of cases that led to NGO reports than in the general population (13.14\% as opposed to $6.64 \%) .{ }^{47}$ Table 1 also shows more violations of Article 3's prohibition of torture and inhuman treatment in the group of judgments that led to NGO reports than in the general population $(27.74 \%$

46. The Two-Tailed Fisher's Exact Test for establishing statistical significance is especially useful with small sample sizes and can calculate exact $P$ values. The results throughout this Article were checked by the author using GraphPad software available at http://graphpad.com/quickcalcs/contingency1.cfm [https://perma.cc/6WQU-JSBU] (data on file with author).

47. P value of 0.0056 (indicating a statistically significant difference). 
as opposed to $18.48 \%) .{ }^{48}$ These differences are statistically significant. Violations of Articles 2 and 3 are generally considered the most severe violations under the ECHR's jurisdiction, and states cannot derogate from these Articles, even in times of emergency. ${ }^{49}$

Furthermore, there are more violations of Article 13 that concern failing to supply victims with an effective remedy in the group of cases that led to NGO reports than in the general population of judgments $(20.44 \%$ as opposed to $12.23 \%) .{ }^{50}$ An even greater difference between the two groups concerns violations of Article 14 requiring states to give equal treatment $(13.14 \%$ as opposed to $2.01 \%) .{ }^{51}$ These differences are also statistically significant. Applicants often accuse states of violating their rights under Articles 13 or 14 in addition to the main violation covered by another article of the Convention. Usually, the ECHR decides that finding an additional violation besides the main violated article is unnecessary. But in rare cases when the discrimination of the applicants is severe or when the state doesn't provide any good remedy, the ECHR finds a violation of these articles as well. Accordingly, the existence of Article 13 and Article 14 violations can serve as a good proxy for the existence of severe and pervasive human rights violations.

The first method of analyzing the data finds significant differences supporting the conclusion that NGOs usually file reports on more severe cases. These are either cases that deal with the most severe types of human rights violations or cases that reveal additional problems, such as discrimination or a lack of an effective remedy for the violation. The second method of analysis can also be used here. However, the data about NGO attention in cases in which at least one NGO report was filed isn't conclusive regarding some of the articles examined. It only suggests that NGOs focus special attention on violations that are severe due to the discrimination they entail between social groups, and therefore involve an Article 14 violation. ${ }^{52}$

48. $\mathrm{P}$ value of 0.0102 (indicating a statistically significant difference).

49. See The Convention, supra note 8 at art. 15(2); see also Natasa Mavronicola, What is an Absolute Right? Deciphering Absoluteness in the Context of Article 3 of the European Convention on Human Rights, 12 Hum. RTS L. REV. 723, 757 (2012) (arguing that Article 3 protects an absolute right that states cannot digress from regardless of the implications).

50. $\mathrm{P}$ value of 0.0081 (indicating a statistically significant difference).

51. $\mathrm{P}$ value of less than 0.0001 (indicating a statistically significant difference).

52. Cases that drew minimal NGO attention included $18.52 \%$ of Article 2 violations, $24.07 \%$ of Article 3 violations, $18.52 \%$ of Article 13 violations, and 5.56\% of Article 14 violations. Cases that drew special NGO attention included $10.53 \%$ of Article 2 violations, $34.21 \%$ of Article 3 violations, $28.95 \%$ of Article 13 violations, and $26.32 \%$ of Article 14 violations. Unexpectedly, therefore, there are more Article 2 violations in cases that drew minimal NGO attention than in cases that drew special NGO attention. Yet this difference is not statistically significant ( $\mathrm{P}$ value of 0.3828 ). Although there seem to be more Article 3 and Article 13 violations in cases that drew special NGO attention, the differences 


\section{Just Satisfaction}

Another proxy for the severity of the violation is the "just satisfaction" granted by the court. Just satisfaction compensates the applicant only for harms that will not be redressed by compliance with the court's decree. As a result, it is not a perfect proxy for the severity of the violation. Some violations may be very severe and lead to great harm if continued, such as an unjustified arrest, but will lead to small amounts of compensation for damage already incurred. In other cases, the ECHR may address violations involving economic issues that do not raise acute human rights concerns but nonetheless lead to high sums of compensation. With these caveats in mind, it may be useful to consider just satisfaction as a rough proxy for the severity of violations. This raises the question: which types of cases do NGOs focus on, as illustrated by the amounts granted by the ECHR in just satisfaction? Comparing cases that led to minimal and to special NGO attention can provide meaningful insight. Table 2 presents this data together with the figures for the entire group of cases that led to NGO reports. ${ }^{53}$

Table 2: Amounts of Just Satisfaction in Judgments that Led to Special NGO Attention

\begin{tabular}{|l|l|l|l|}
\hline $\begin{array}{l}\text { Sum of Just Satisfaction } \\
\text { (in Euros) }\end{array}$ & $\begin{array}{l}\text { All Cases Leading } \\
\text { to NGO Reports }\end{array}$ & $\begin{array}{l}\text { Minimal NGO } \\
\text { Attention }\end{array}$ & $\begin{array}{l}\text { Special NGO } \\
\text { Attention }\end{array}$ \\
\hline None & $13.87 \%$ & $9.26 \%$ & $10.53 \%$ \\
\hline Less than 1,000 & $3.65 \%$ & $3.70 \%$ & $5.26 \%$ \\
\hline $1,000-10,000$ & $35.04 \%$ & $38.89 \%$ & $13.16 \%$ \\
\hline $10,001-100,000$ & $35.77 \%$ & $35.19 \%$ & $50.00 \%$ \\
\hline More than 100,000 & $11.68 \%$ & $12.96 \%$ & $21.05 \%$ \\
\hline
\end{tabular}

In cases with more than 10,000 Euros in just satisfaction, there is a tendency for those cases with special NGO attention to involve higher just satisfaction than cases with minimal NGO attention. This difference is statistically significant at the 0.05 level. ${ }^{54}$

concerning these articles are not statistically significant ( $\mathrm{P}$ values of 0.3495 and 0.3142 , respectively). In contrast, the difference regarding Article 14, which is more common in cases of special NGO attention, is statistically significant at the 0.01 level (P value of 0.0066 ).

53. For an analysis of the harms compensated for by just satisfaction, see OCTAVIAN ICHIM, JUST SATISFACTION UNDER THE EUROPEAN CONVENTION ON HUMAN RIGHTS 98-121 (2015). The court has especially wide discretion in determining non-pecuniary damages. $I d$. at 121 . To provide a sense of the amount of just satisfaction typically granted by the ECHR, the median sum awarded for the most severe violation, violation of the right to life under Article 2, is around 20,000-30,000 Euros. See id. at 128. Compensation for inappropriate detention conditions is often less than 10,000 Euros. Id. at 129 .

54. P value of 0.0338 . However, comparing the relative part of cases with more than 100,000 Euros just satisfaction in cases that led to minimal and to special NGO attention does not yield statistically significant results ( $\mathrm{P}$ value of 0.3922 ). 
The analysis so far supports the view that reputational sanctions are not merely a source of annoyance, but rather focus on issues of real concern. Yet the question remains whether the cases that draw the attention of NGOs are also cases of greater legal importance.

\section{B. The Legal Importance of the Case}

Cases involving severe violations are not necessarily legally important. A case could address the most terrible human rights violations and at the same time involve no novel legal argument. In fact, important cases can address relatively mild human rights violations. For example, the ECHR's Von Hannover case ${ }^{55}$ that addressed the permissibility of publishing paparazzi pictures of the princess of Monaco is a very important case because of its innovative legal analysis of the proper balance between privacy and freedom of the press. However, the violation this case addresses isn't severe compared to the cases the ECHR regularly handles.

Establishing the legal importance of a case seems like a tricky taskone that requires great doctrinal skill and legal understanding. Fortunately, there are many good proxies for the importance of cases, some of which are addressed in this sub-part.

\section{HUDOC Categorization}

The HUDOC database divides cases into four levels according to their importance: Case Reports, and Importance Levels 1, 2, and 3. Case Reports cases are selected for official publication. They are usually the most important cases in terms of their legal significance. Level 1 cases are unpublished cases that contributed significantly to the development, modification, or clarification of the ECHR's case law. Level 2 cases are of medium importance; they do not make a significant contribution, but go somewhat beyond mere application of existing case law. Level 3 cases are cases of low importance; they merely apply case law and do not change it. ${ }^{56}$

Cases that led to NGO reports are more likely to be categorized as either Case Reports ${ }^{57}$ or as Level 1 cases. ${ }^{58}$ While most of the cases the ECHR decides are in the Level 3 category of importance-merely applying the law-more than half of the cases that led to NGO reports are published or

55. See generally Von Hannover v. Germany, 2004-III Eur. Ct. H.R. 1.

56. See Eur. Ct. OF H.R., HUDOC USER MANUAL 11-12 (2012), http://www.echr.coe.int/Docume nts/HUDOC_Manual_2012_ENG.pdf [https://perma.cc/2YA4-792D].

57. $\mathrm{P}$ value of less than 0.0001 (indicating a statistically significant difference).

58. $\mathrm{P}$ value of less than 0.0001 (indicating a statistically significant difference). The cases that led to NGO reports are obviously even more likely to be categorized in these two categories (case reports and Importance Level 1) taken together (statistically significant difference, P value of less than 0.0001) than cases in the general population. 
contribute significantly to the court's case law and are therefore classified in the Case Reports or Level 1 categories. ${ }^{59}$

The data also suggest that cases that draw special NGO attention are usually more important than cases that draw minimal NGO attention-they are significantly more likely to be categorized as Case Reports ${ }^{60}$ or Level 1 cases $^{61}$-indicating that NGOs focus more attention on important cases. ${ }^{62}$

\section{The Size of the Panel}

Given that only cases of extreme legal importance are decided by the Grand Chamber, ${ }^{63}$ another method of measuring a case's importance is to check if the case was decided by a Chamber or by a Grand Chamber. In the general population, only $0.81 \%$ of the cases were Grand Chamber judgments while $99.19 \%$ were Chamber judgments. ${ }^{64}$ Contrast that with the cases that led to NGO reports. There are 137 cases in the group. Only one of them was issued by a Committee of three judges and was excluded from the analysis. ${ }^{65}$ Excluding this case, the group included $15.33 \%$ (21) Grand Chamber judgments ${ }^{66}$ and $83.94 \%$ (115) Chamber judgments. The difference between the groups is statistically significant. ${ }^{67}$ This supports the conclusion that a far greater proportion of the cases that led to NGO reports involved questions of

59. The importance levels of cases in the general population were divided as follows: Case Reports (1.56\%); Importance Level 1 (2.70\%); Importance Level 2 (17.25\%); and Importance Level 3 (78.49\%). From 5,584 cases in the general population, the cases divided as follows: 87 Case Reports; 151 Importance Level 1 cases; 963 Importance Level 2 cases; and 4,383 Importance Level 3 cases). Contrast that with the distribution of the cases that led to NGO reports: Case Reports (31.39\%); Importance Level 1 cases (18.98\%); Importance Level 2 cases (35.04\%); and Importance Level 3 cases (14.60\%). Those percentages represent, from a total of 137 cases that led to NGO reports, 43 Case Reports; 26 Importance Level 1 cases; 48 Importance Level 2 cases; and 20 Importance Level 3 cases. The differences are clear.

60. $\mathrm{P}$ value of 0.0008 .

61. P value of 0.0124 . The difference between the proportions of cases in these two categories combined has a $\mathrm{P}$ value of less than 0.0001 .

62. Cases that drew minimal NGO attention were distributed as follows: Case Reports $18.52 \%$; Importance Level 1 cases (9.26\%); Importance Level 2 cases (44.44\%); and Importance Level 3 cases (27.78\%). Cases that drew special NGO attention were distributed as follows: Case Reports (52.63\%); Importance Level 1 cases (31.58\%); Importance Level 2 cases (15.79\%); and Importance Level 3 cases $(0 \%)$.

63. See commentary, supra note 17 .

64. From 5,584 cases in the general population, 45 are Grand Chamber judgments and 5,539 are Chamber judgments.

65. All such cases are deliberately not part of the general population to exclude technical cases issued after Protocol 14 went into force.

66. Of these cases, eleven were decided only by a Grand Chamber based on a referral by the Chamber and ten cases were decided by the Grand Chamber after a previous Chamber decision and a request by the parties.

67. $\mathrm{P}$ value of less than 0.0001 . 
great legal significance that were discussed by the Grand Chamber, compared to the rest of the cases issued by the ECHR.

Similarly, there is a significantly greater proportion of Grand Chamber cases in the group of cases that led to special NGO attention as compared to cases that led to minimal NGO attention. ${ }^{68}$ This suggests that NGOs focus their attention on cases of greater legal importance, which are more likely to be decided by the Grand Chamber.

\section{Judicial Dialogue}

Another proxy for a case's legal importance is the level of dialogue among judges. Most judgments of the ECHR are issued unanimously. But sometimes judges dissent or write concurring opinions. These cases are usually more legally significant; otherwise, the judges would not be in dispute or at least would not dedicate the time necessary to write a separate opinion. In the general population, only $10.89 \%$ of the judgments contained at least one separate opinion. In contrast, $35.77 \%$ of the judgments that led to NGO reports contained at least one separate opinion. ${ }^{69}$ This difference is statistically significant. $^{70}$

In cases that led to minimal NGO attention, $24.07 \%$ contained at least one separate opinion. In cases that attracted special NGO attention, 57.89\% contained at least one separate opinion. This difference is also statistically significant. ${ }^{71}$ These results suggest that NGOs focus their attention on issues of special legal significance, where judges are usually more inclined to present their views by way of a separate opinion.

\section{Other Proxies for Salience}

After judgments are issued by the ECHR, the CM categorizes them in a way that will aid the monitoring of compliance. In 2012, from the 11,099 cases pending before the CM, only 1,431 (12.9\%) were Leading Cases-

68. Cases that led to minimal NGO attention were divided as follows: $1.85 \%$ (one judgment) issued by a committee (which was thus excluded from the analysis); $9.26 \%$ involved Grand Chamber judgments; and $88.89 \%$ involved Chamber judgments. In contrast, cases that led to special NGO attention were divided as follows: $36.84 \%$ involved Grand Chamber judgments and $63.16 \%$ involved Chamber judgments. The difference between the groups is statistically significant ( $\mathrm{P}$ value of 0.0032 ). As noted above, the significance test excludes the case involving a judgement issued by a committee.

69. Of the 5584 judgments in the general population, 608 contained a separate opinion. Of the 137 judgments that led to NGO reports, 49 contained at least one separate opinion. Many of the judgments with NGO reports attracted a significant number of separate opinions: $10.22 \%$ of the judgments attracted three or more dissenting judges, while $5.11 \%$ attracted three or more concurring judges.

70. $\mathrm{P}$ value of less than 0.0001 .

71. $\mathrm{P}$ value of 0.0020 . 
namely, cases which raise so-called "general structural problems."72 Contrast that with the data on judgments that drew NGO reports: $91(76.47 \%)$ of the 119 judgments that were still pending on January 2015 were categorized as Leading Cases. This difference is statistically significant, ${ }^{73}$ but it is important to note that the CM may tend to categorize cases as Leading Cases because they drew NGO attention, which suggests a potential problem of reversed causality. ${ }^{74}$ Of the cases that led to minimal NGO attention, $57.45 \%$ were Leading Cases. Of cases that led to special NGO attention, $91.18 \%$ were Leading Cases. This difference is statistically significant. ${ }^{75}$

It may be useful to compare judgments that drew minimal NGO attention to judgments that drew special NGO attention according to their propensity to lead to interim resolutions by the $\mathrm{CM}$. Interim resolutions are the primary way for the $\mathrm{CM}$ to direct reputational sanctions against recalcitrant states. It is reasonable to assume that this tool is reserved for issues that are of the highest concern to the CM; therefore, if cases with interim resolutions draw increased NGO attention, this may suggest that NGOs focus on severe violations. Only $7.41 \%$ of the cases that drew minimal $\mathrm{NGO}$ attention led to one interim resolution. None of the cases in this group led to more than one interim resolution. In contrast, in cases that led to special NGO attention, $10.53 \%$ led to one interim resolution, $7.89 \%$ led to two interim resolutions, and $5.26 \%$ led to three interim resolutions. If the propensity to generate at least one interim resolution is compared within the two groups, the difference between them is statistically significant. ${ }^{76}$ This understates the difference, of course, as the data reveals that only issues with special NGO attention sometimes led to more than one interim resolution. Despite the apparent difference, it is important to caution that the CM may decide to issue interim resolutions based on the shaming efforts of NGOs or

72. In 2011 this figure is roughly the same - from 10,689 cases pending there were $1,337(12.51 \%)$ Leading Cases.

73. $\mathrm{P}$ value of less than 0.0001 . This significance test is unique: It does not refer to the general population of judgments referred to throughout this Article but instead to cases categorized by the CM as explained above. Furthermore, because of the very large sample, a different statistical test was used this time-Chi-square with Yates correction. In this case, Chi squared equals 400.429 with one degree of freedom.

74. Some of the cases that led to NGO reports were closed by the CM and are therefore not categorized either as a Leading Case or not. An additional $20.17 \%$ of the cases that led to NGO reports were grouped with another Leading Case; in this group of cases, though the case may not be the prime representative of the structural problem, it is related to a problem that led to another Leading Case.

75. $\mathrm{P}$ value of 0.0010 . Seven judgments that led to NGO reports $(5.11 \%)$ are Pilot Cases. Five of them are cases with special NGO attention, and none of them is a case with minimal NGO attention. These cases not only involve a structural problem - the problem is so severe or widespread that the court issued a specific decree detailing how the state should act to remedy it. This novel procedure has only been used in a handful of cases in the court's history.

76. $\mathrm{P}$ value of 0.0355 . 
on the behavior of the state itself, which could, in turn, also be affected by NGO reports. In fact, several NGO activists insisted in interviews that the $\mathrm{CM}$ issued an interim resolution because of the reports they filed and the pressure they exerted on it to monitor state compliance. ${ }^{77}$ Therefore, causal connections here are murky. ${ }^{78}$

\section{Conclusions on the Focus of NGO Attention}

The preceding sub-parts provide evidence that NGOs focus their efforts on cases that expose severe violations and that are legally important. This supports the view that reputational sanctions are meaningful. The agents imposing these sanctions by shaming wrongdoers do not focus on trivial matters. They are concerned with important issues of human rights.

\section{WHICH TYPE OF STATES DRAW THE MOST NGO ATTENTION?}

Are reputational sanctions targeted primarily against states that typically fail to comply with human rights norms, so-called "low-reputation states"? Or, do sanctions target states with a reputation for enforcing human rights standards, so called "high-reputation states"? A finding that for every case issued against a high-reputation state there is a greater chance that NGOs will file reports than for a case issued against a low-reputation state would support the hypothesis that reputational sanctions focus primarily on states with a high reputation. ${ }^{79}$

\section{A. Measuring States' Reputation}

Before addressing the question of which states are usually targeted by reputational sanctions, it is first necessary to categorize states according to

77. This information (and all other interview-related information in this article) is derived from interviews conducted by the author. The author agreed not to mention interviewees by name and that transcripts of the interviews will not be circulated. As such, any and all assertions remain unverified by the editor. Skype Interview: NGO activist 8, (May 20, 2015); Skype Interview: Official at the Russian Justice Initiative (June 1, 2015).

78. Another method to check the concern of the CM is the decision to direct a case to the enhanced supervision track instead of the standard supervision track. Only cases that require greater monitoring attention or urgent action, or that involve serious structural problems, are reviewed under enhanced supervision. Of the forty-seven cases with minimal NGO attention that were still pending on January 2015, thirty-three $(70.21 \%)$ are under enhanced supervision. Of the thirty-four cases with special NGO attention still pending at the time, twenty-five (73.53\%) are under enhanced supervision. This difference is not statistically significant ( $\mathrm{P}$ value of 0.8066 ).

79. If all reports are focused on low-reputation states, this would imply that they are the most vulnerable to such accusations. If many but not all reports are focused on low-reputation states, this does not necessarily imply that high-reputation states are immune from reputational sanctions; after all, lowreputation states are responsible for an immense majority of the violations. 
their levels of reputation. But any such attempt is subject to accusations of bias. Many people probably have some intuitions about which countries abide by international law and which ignore it most of the time. But these intuitions can be wrong. They could result from stereotypes rather than from real data. In contrast, information about a state's level of democracy, ${ }^{80}$ freedom, ${ }^{81}$ or corruption ${ }^{82}$ may be quite accurate, but it may have little to do with the state's propensity to comply with international law.

To measure the actual tendency of states to comply with the ECHRas a useful substitute for the elusive perceptions of the international community about these states' behavior that really constitute their reputation - this Article constructs a new metric. ${ }^{83}$ This metric is developed by gathering data on six different facts relating to states:

1. The number of pending cases allocated to a judicial formation on December 31, 2012. ${ }^{84}$

2. The number of judgments finding at least one violation in $2012 .^{85}$

3. The number of judgments finding at least one violation between 1959 and $2012 .{ }^{86}$

4. The number of cases pending at the CM (supervising compliance) in $2012 .{ }^{87}$

5. The number of Leading Cases pending at the CM in $2012 .{ }^{88}$

80. See, e.g., DEMOCRACY RANKING, http://democracyranking.org/ (an example of an organization that provides an annual ranking of all country-based democracies. This organization tests the strength of each country's democracy based on one political dimension and five non-political dimensions: (1) gender (socio-economic and educational gender equality); (2) economy (economic system); (3) knowledge (knowledge-based information society, research and education); (4) health (health status and health system); and (5) environment (environmental sustainability).

81. See FREEDOM HousE, https://www.freedomhouse.org/ (independent watchdog agency that publishes analysis of the state of political liberties and civil rights in nations across the world).

82. See Corruption by Country/Territory, TRANSPARENCY INTERNATIONAL, http://www.transparen cy.org/country (organization that investigates corruption in countries around the world and publishes an annual Corruption Perceptions Index).

83. Part V investigates reasons why the beliefs held by the international community about states' behavior may be wrong or systematically biased. Despite these potential risks, which Part V argues are somewhat alleviated by the nature of the human rights community, the actual behavior of the state remains the best possible proxy for its reputation.

84. Data from EUR. CT. H.R, ANNUAL REPORT 2012, 150 (2013), http://www.echr.coe.int/Documen ts/Annual_report_2012_ENG.pdf [https://perma.cc/6R4C-M5FF].

85. Id. at $154-55$.

86. Id. at $158-59$.

87. Council of Europe COMMITTEe of Ministers, Supervision of THE EXECUTION OF JUDGMENTS AND DECISIONS OF THE EUROPEAN COURT OF HUMAN RIGHTS - 6TH ANNUAL REPORT OF THE COMMITTEE OF MINISTERS 2012, 45-47 (2013), https://rm.coe.int/CoERMPublicCommonSearchSer vices/DisplayDCTMContent?documentId=0900001680592ac8 [https://perma.cc/UA9F-7S5X].

88. Id. 
6. The number of pending cases awaiting confirmation of payment of just satisfaction at the end of $2012 .{ }^{89}$

All of these indicators aim to address the states' human rights practices that are detected by the international community and thus translate into the states' reputation. Each indicator is designed to counter the biases of the other measures. The number of judgments that find violations seems like a good measure of compliance with the Convention, but it is exposed to the accusation that the court itself is biased in favor of some states and against others and is consequently likely to find certain states in violation more often. ${ }^{90}$ The number of cases filed against states may counter this potential bias, yet it is possible that applicants target more cases against states that are disfavored by the ECHR, thereby improving their chances of victory. Finally, the last three measures aim to assess the compliance of states with the ECHR's judgments themselves, rather than compliance with the Convention. The number of cases as well as the number of Leading Cases awaiting compliance at the $\mathrm{CM}$ are both relevant measures, as they address both the raw number of applications and a good proxy for the number of structural problems that led to Leading Cases. Non-payment of just satisfaction is an additional indicator of unwillingness to comply.

All indicators are highly correlated with one another; ${ }^{91}$ suggesting that they all reveal the same quality: the general willingness of a given state to comply with international law. This quality is presumably perceived by the international community and forms the state's reputation.

For each indicator, the forty-seven countries comprising the Council of Europe were divided into five groups. The ten countries with the best practices are categorized as 1 , the next ten as 2 , etc. The last group - the states with the worst practices-includes only seven states. After states receive a number with respect to each metric, the six numbers are averaged and the result rounded to the nearest whole number to obtain the state's final reputational score between 1 and 5 -where 5 indicates the states with the worst reputations. ${ }^{92}$ This proxy of the state's reputation may not be perfect, but it comes as close as possible to an objective measure of any given state's willingness to comply with international law.

89. Id. at $57-59$.

90. See generally Dothan, supra note 25 (arguing that the ECHR is more willing to find lowreputation states in violation of the Convention compared to high-reputation states).

91. The CORREL function in Excel was used to calculate the correlation between the propensity of states to be in one of the groups (1-5) mentioned in the next paragraph, according to each one of the six indicators. The lowest correlation was between indicators 1 and $6(66.8 \%)$. The average of the correlations between all possible pairs of indicators was $80.9 \%$.

92. There are fewer states in the 5 group for each metric, making this score a potent signal of the state's bad practices. 
The information on states with reputation levels 1 and 2 can safely be disregarded. First, very few cases involving these states have been brought before the ECHR - less than 3\% of the cases in the general population, as table 5 below shows. This provides no real opportunity to file NGO reports; indeed only one case that led to NGO reports involved a state of reputation level 2, and no such case involved a state of reputation level 1. Second, the populations of the countries with reputation levels 1 and 2 are very small. Some of these countries can be credited with a high reputation level because they usually comply with their Convention obligations, but many just have a miniscule citizenry and fewer occasions for violations. ${ }^{93}$

Excluding countries with reputation levels 1 and 2 from the analysis leaves only the comparison between eight states with reputation level 5, which can be called "low-reputation states," and twenty-three states with reputation levels 3 and 4, which can be called "high-reputation states."

This empirical metric is consistent with long-held views about the nature of states in Europe. It is telling that Russia, Poland, Turkey, and Romania which were nicknamed the "Big Four"- because they are known for being responsible for the most cases before the $\mathrm{ECHR}^{94}$ — are all coded as low-reputation states. Most of the other results of this metric sit well with intuition and with less systematic methods to address the behavior of states in Europe. ${ }^{95}$

\section{B. The Connection Between State Reputation and NGO Applications}

A quick glance at the states that led to NGO reports appears to support the hypothesis that NGOs focus on low-reputation states. Countries with low reputations are indeed targeted by most of the NGO reports filed. However, these countries are also responsible for most of the judgments that the ECHR has issued. Table 3 summarizes data on the number of judgments against different types of states and the corresponding number of judgments against them that led to reports.

93. Of the sixteen countries in reputation levels 1 and 2 , six have a population smaller than half a million. The country with the smallest population is San Marino, with just 32,000 citizens. The average population of all states in levels 1 and 2 is 3,354,125 and their combined population is just 53,666,000smaller than the population of Germany or the United Kingdom, which both have a reputation level of 3. Population Figures by Country, ONE WORLD NATIONS ONLINE, http://www.nationsonline.org/oneworld/ population-by-country.htm [https://perma.cc/H6S2-79WW].

94. See Luzius Wildhaber, The European Court of Human Rights: The Past, The Present, The Future, 22 AMER. U. INT'L L. REV. 521, 527 (2007).

95. See Shai Dothan, Reputation and Judicial Tactics: A TheOry of National AND INTERNATIONAL COURTS 239-42 (2015) (analyzing data about the human rights compliance of states in Europe without developing a systematic metric of states reputation). 
Table 3: The States, Their Reputations, the Judgments Issued Against Them and the Judgments that Led to Reports

\begin{tabular}{|c|c|c|c|c|c|}
\hline $\begin{array}{l}\text { Reputation } \\
\text { Level }\end{array}$ & State & $\begin{array}{l}\text { Number of } \\
\text { Judgments } \\
\text { - General } \\
\text { Population }\end{array}$ & $\begin{array}{l}\text { Percentage } \\
\text { of } \\
\text { Judgments } \\
\text { - General } \\
\text { Population }\end{array}$ & $\begin{array}{l}\text { Number of } \\
\text { Judgments } \\
\text { with NGO } \\
\text { Reports }\end{array}$ & $\begin{array}{l}\text { Percentage } \\
\text { of } \\
\text { Judgments } \\
\text { with NGO } \\
\text { Reports }\end{array}$ \\
\hline 3 & Albania & 23 & $0.41 \%$ & 1 & $0.73 \%$ \\
\hline 1 & Andorra & 2 & $0.04 \%$ & 0 & 0 \\
\hline 3 & Armenia & 25 & $0.45 \%$ & 9 & $6.57 \%$ \\
\hline 3 & Austria & 57 & $1.02 \%$ & 0 & 0 \\
\hline 4 & Azerbaijan & 37 & $0.66 \%$ & 13 & $9.49 \%$ \\
\hline 3 & Belgium & 40 & $0.72 \%$ & 1 & $0.73 \%$ \\
\hline 3 & $\begin{array}{l}\text { Bosnia and } \\
\text { Herzegovina }\end{array}$ & 19 & $0.34 \%$ & 2 & $1.46 \%$ \\
\hline 5 & Bulgaria & 247 & $4.42 \%$ & 8 & $5.84 \%$ \\
\hline 4 & Croatia & 90 & $1.61 \%$ & 4 & $2.92 \%$ \\
\hline 2 & Cyprus & 14 & $0.25 \%$ & 0 & 0 \\
\hline 4 & $\begin{array}{l}\text { Czech } \\
\text { Republic }\end{array}$ & 55 & $0.98 \%$ & 1 & $0.73 \%$ \\
\hline 1 & Denmark & 6 & $0.11 \%$ & 0 & 0 \\
\hline 2 & Estonia & 15 & $0.27 \%$ & 0 & 0 \\
\hline 3 & Finland & 57 & $1.02 \%$ & 0 & 0 \\
\hline 4 & France & 126 & $2.26 \%$ & 5 & $3.65 \%$ \\
\hline 3 & Georgia & 28 & $0.50 \%$ & 4 & $2.92 \%$ \\
\hline 3 & Germany & 66 & $1.18 \%$ & 0 & 0 \\
\hline 5 & Greece & 241 & $4.32 \%$ & 3 & $2.19 \%$ \\
\hline 4 & Hungary & 123 & $2.20 \%$ & 1 & $0.73 \%$ \\
\hline 1 & Iceland & 3 & $0.05 \%$ & 0 & 0 \\
\hline 2 & Ireland & 2 & $0.04 \%$ & 1 & $0.73 \%$ \\
\hline 5 & Italy & 229 & $4.10 \%$ & 3 & $2.19 \%$ \\
\hline 3 & Latvia & 38 & $0.68 \%$ & 1 & $0.73 \%$ \\
\hline 1 & Liechtenstein & 0 & $0.00 \%$ & 0 & 0 \\
\hline 3 & Lithuania & 37 & $0.66 \%$ & 1 & $0.73 \%$ \\
\hline 1 & Luxembourg & 13 & $0.23 \%$ & 0 & 0 \\
\hline 2 & Malta & 22 & $0.39 \%$ & 0 & 0 \\
\hline 4 & $\begin{array}{l}\text { Republic of } \\
\text { Moldova }\end{array}$ & 123 & $2.20 \%$ & 3 & $2.19 \%$ \\
\hline 1 & Monaco & 2 & $0.04 \%$ & 0 & 0 \\
\hline 2 & Montenegro & 14 & $0.25 \%$ & 0 & 0 \\
\hline 2 & Netherlands & 11 & $0.20 \%$ & 0 & 0 \\
\hline 1 & Norway & 8 & $0.14 \%$ & 0 & 0 \\
\hline 5 & Poland & 395 & $7.07 \%$ & 21 & $15.31 \%$ \\
\hline 4 & Portugal & 58 & $1.04 \%$ & 0 & 0 \\
\hline 5 & Romania & 584 & $10.46 \%$ & 5 & $3.65 \%$ \\
\hline 5 & $\begin{array}{l}\text { Russian } \\
\text { Federation }\end{array}$ & 899 & $16.10 \%$ & 23 & $16.79 \%$ \\
\hline 1 & San Marino & 1 & $0.02 \%$ & 0 & 0 \\
\hline 4 & Serbia & 51 & $0.91 \%$ & 3 & $2.19 \%$ \\
\hline
\end{tabular}




\begin{tabular}{|l|l|l|l|l|l|}
\hline 3 & Slovak & & & & \\
\hline 4 & Republic & 109 & $1.95 \%$ & 0 & 0 \\
\hline 3 & Slovenia & 50 & $0.90 \%$ & 1 & $0.73 \%$ \\
\hline 2 & Spain & 37 & $0.66 \%$ & 2 & $1.46 \%$ \\
\hline 2 & Sweden & 13 & $0.23 \%$ & 0 & 0 \\
\hline & Switzerland & 31 & $0.56 \%$ & 0 & 0 \\
& $\begin{array}{l}\text { The former } \\
\text { Yugoslav } \\
3\end{array}$ & & & & \\
\hline 5 & $\begin{array}{l}\text { Republic of } \\
\text { Macedonia }\end{array}$ & 61 & $1.09 \%$ & 0 & 0 \\
\hline 5 & Turkey & 1046 & $18.73 \%$ & 9 & $6.57 \%$ \\
\hline 3 & Ukraine & 424 & $7.59 \%$ & 3 & $2.19 \%$ \\
\hline Total: & United & 73 & $1.31 \%$ & 10 & $7.3 \%$ \\
\hline
\end{tabular}

To provide a clearer view of the types of states that NGOs focus on, Table 4 groups states according to their levels of reputation. The table illustrates the proportion of judgments in the general population that are targeted at states of every reputation level, and the corresponding proportions in cases that led to NGO reports.

Table 4: The Proportion of Judgments and the Judgments that Led to NGO reports Conditioned on the States' Reputations

\begin{tabular}{|l|l|l|l|}
\hline \hline $\begin{array}{l}\text { State Average Level } \\
\text { of Reputation }\end{array}$ & $\begin{array}{l}\text { Percentage of } \\
\text { Judgments from } \\
\text { General Population }\end{array}$ & $\begin{array}{l}\text { Percentage of } \\
\text { Judgments that } \\
\text { Led to NGO } \\
\text { Reports }\end{array}$ & $\begin{array}{l}\text { Ratio of Judgments } \\
\text { with Reports to } \\
\text { Judgments in the } \\
\text { General Population }\end{array}$ \\
\hline 1 (Disregard) & $0.63 \%$ & $0 \%$ & $0.73 \%$ \\
\hline 2 (Disregard) & $2.18 \%$ & $22.63 \% 97$ & $\mathbf{1 . 8 9}$ \\
\hline 3 (High Reputation) & $12.00 \%$ & $22.63 \%$ & $\mathbf{1 . 7 7}$ \\
\hline 4 (High Reputation) & $12.77 \%$ & $54.73 \%$ & $\mathbf{0 . 7 5}$ \\
\hline 5 (Low Reputation) & $72.80 \%$ & &
\end{tabular}

Judgments that led to NGO reports are more likely to be issued against

96. Seven reports concerned a single judgment-M.S.S. v. Belgium and Greece, App. No. 30696/09, EUR. CT. H.R. (2011). This case is coded here twice, once as a Greek case and once as a Belgian case. Besides the data in Tables 3 and 4, the case was coded as addressing only Greece, which is the more direct applicant. The applicant in this case is an asylum seeker. The court found that the conditions of his detention in a Greek holding center and living conditions in Greece violated Article 3 to the Convention. Belgium violated Article 3 by the act of transferring the applicant to Greece-certainly a more incidental violation. Furthermore, the case against Belgium, but not against Greece, was closed by the CM on December 4, 2014. CM/ResDH (2014)272. Judgments addressing more than one state are rare but sometimes exist. This explains why the number of judgments leading to NGO reports and the judgments in the general population of cases sum to more than $100 \%$.

97. Or $21.90 \%$ when M.S.S. v. Belgium and Greece is coded as addressing Greece alone. See id. $21.90 \%$ is the figure used for the significance test. This choice makes proving the hypothesis that highreputation states are subject to more judgments harder (and consequently its proof more convincing) because Belgium is a high-reputation state and Greece is a low-reputation state. 
high-reputation states and not low-reputation states compared to judgments in the general population. In fact, only $24.77 \%$ of the judgments in the general population address high-reputation states, compared to $45.26 \%$ of the judgments in the group that led to NGO reports. This difference is statistically significant. ${ }^{98}$ This demonstrates that NGOs are more likely to direct their efforts toward cases issued against high-reputation states than against low-reputation states.

It is now possible to check the amount of attention NGOs devote to cases conditioned on the state's reputation.

Table 5: The Attention NGOs Devote to Cases Conditioned on the States' Reputation

\begin{tabular}{|l|l|l|l|}
\hline \hline $\begin{array}{l}\text { State Average Level } \\
\text { of Reputation }\end{array}$ & $\begin{array}{l}\text { Percentage of } \\
\text { Judgments that Led } \\
\text { to Minimal NGO } \\
\text { Attention }\end{array}$ & $\begin{array}{l}\text { Percentage of } \\
\text { Judgments that } \\
\text { Led to Special } \\
\text { NGO } \\
\text { Attention }\end{array}$ & $\begin{array}{l}\text { Ratio of Judgments } \\
\text { with } \\
\text { Special Attention } \\
\text { to Judgments with } \\
\text { Minimal } \\
\text { Attention }\end{array}$ \\
\hline 1 (Disregard) & $0 \%$ & $0 \%$ & \\
\hline 2 (Disregard) & $0 \%$ & $2.63 \%$ & \\
\hline 3 (High Reputation) & $18.52 \%$ & $26.32 \%$ & $\mathbf{1 . 4 2}$ \\
\hline 4 (High Reputation) & $25.93 \%$ & $18.42 \%$ & $\mathbf{0 . 7 1}$ \\
\hline 5 (Low Reputation ) & $55.56 \%$ & $52.63 \%$ & $\mathbf{0 . 9 5}$ \\
\hline
\end{tabular}

When the likelihood of judgments that led to special NGO attention to be directed at high-reputation states and not low-reputation states is compared to the corresponding likelihood in judgments that led to minimal

98. $\mathrm{P}$ value of less than 0.0001 (comparing reputation levels 3 and 4 combined to reputation level 5 , and excluding reputation levels 1 and 2). This highly significant result occurs despite the fact that the test includes data from all the low-reputation states examined including Poland, a clear outlier. Poland is responsible for $7.07 \%$ of the judgments in the general population, but $15.31 \%$ of the judgments with NGO reports. Despite being a low-reputation state, it therefore shows a special propensity to attract NGO reports. This propensity, the reason Poland is such an outlier, may be that Poland showed remarkable willingness to cooperate with the $\mathrm{CM}$ - a factor which, as explained in the next sub-part, may independently explain the willingness of NGOs to file reports against a state. Out of the 21 judgments against Poland that led to reports, Poland responded to all NGO reports concerning a judgment in $71.43 \%$ of the cases and to some of the reports in an extra $4.76 \%$ of the judgments. This contrasts sharply with the corresponding figures in all the judgments that led to NGO reports: $37.96 \%$ and $11.68 \% .4 .76 \%$ of the judgments against Poland resulted in action reports filed within 6 months of the judgments becoming final and another $80.95 \%$ included action reports filed after that time. In all the judgments, the first figure is slightly higher, $13.14 \%$, but the second is much lower- $60.58 \%$. Furthermore, $19.05 \%$ of the judgments against Poland were closed by the CM by January 2015 , while in all the judgments that led to NGO reports the corresponding figure is $13.14 \%$. Including Poland in the pool tilts the results against the hypothesis - towards greater perceived vulnerability of low-reputation states like Poland to NGO attention. That the results are still significant without excluding Poland testifies to their strength.

As a further robustness check, another test was conducted, comparing the data on all non-reputation level 5 states to the data on states with reputation level 5. The result remains statistically significant (Pvalue of less than 0.0001). 
NGO attention, no significant difference emerges. ${ }^{99}$

\section{Alternative Explanations For the Focus of NGOs on High-Reputation States}

This sub-part considers alternative explanations for NGOs' greater likelihood to file reports against high-reputation states, apart from an inherent preference of NGOs for targeting this type of states. Excluding these potential explanations can help determine if NGOs usually target highreputation states beyond the unique framework of the DEJ website procedure.

\section{Willingness to Reply to NGO Reports}

States are allowed to formally respond to NGO reports. Their responses are attached to the report and published in the same file on the CM's website. ${ }^{100}$ States often choose not to respond. A potential reason for the focus of NGOs on high-reputation states is that high-reputation states have functioning democratic institutions that are more likely to take NGO reports seriously and reply to them. If state institutions are likely to respond to NGO reports, this could supply motivation for NGO intervention, because this response creates an opportunity for the NGO to engage in a dialogue with state administrators and to shape their behavior. ${ }^{101}$

A reply does not necessarily indicate that the state is willing to make sacrifices to clear its good name. A state may choose the easy course of replying to accusations that garnered attention instead of amending its ways for the future. Indeed, although some government responses try to refute the accusations lodged against the government by offering countering data, others are technical and easily performed. For example, when the Russian Federation was faced with a report accusing it of abducting a person and forcibly transferring him to Uzbekistan, all its representative wrote in response was that the relevant application "was forwarded to the competent state authorities. In order to verify the statements set out in the application

99. P value of 1.0000 .

100. States sometimes file communications that refer and respond to NGO reports filed a long time before (see for example the communication of the Polish government filed on Oct. 6, 2014 in response to Report (2014)1055 filed on Aug. 22, 2014). For the sake of consistency, such responses were not coded. Only responses formally attached to a report, which — besides in a few very early cases — are joined in the same pdf file, were counted.

101. On the other hand, acting through the CM may be the only way to communicate and receive information from low-reputation countries like Russia, which is otherwise unlikely to collaborate with NGOs. This fact was stressed in an interview with an official at Russian Justice Initiative conducted on June 1, 2015. Even if low-reputation states reveal less information to the CM than do high-reputation states, NGOs may still attempt to draw low-reputation states to respond to the CM, because otherwise they would get no information at all. 
the inquiry is currently in process. Further information will be promptly submitted when the relevant data is received." 102 Such evasive responses are easily produced and certainly do not prove that the state is willing to undertake costly measures to protect its reputation.

Table 6 measures the tendency of states to respond to NGO reports issued against them conditioned on the states' reputation.

Table 6: States' Responses to NGO Reports Conditioned on the States' Reputation

\begin{tabular}{|l|l|l|l|}
\hline \hline Reputation Level & $\begin{array}{l}\text { Respond to } \\
\text { All NGO } \\
\text { Reports }\end{array}$ & $\begin{array}{l}\text { Respond to Some } \\
\text { NGO Reports }\end{array}$ & $\begin{array}{l}\text { No Response to NGO } \\
\text { Reports }\end{array}$ \\
\hline 1 (Disregard) & $0 \%$ & $0 \%$ & $0 \%$ \\
\hline 2 (Disregard) & $0 \%$ & $0 \%$ & $100.00 \%$ \\
\hline 3 (High Reputation) & $46.67 \%$ & $20.00 \%$ & $33.33 \%$ \\
\hline 4 (High Reputation) & $38.71 \%$ & $9.68 \%$ & $51.61 \%$ \\
\hline 5 (Low Reputation) & $34.67 \%$ & $9.33 \%$ & $56.00 \%$ \\
\hline
\end{tabular}

When the tendency of high-reputation states to respond to at least some of the NGO reports filed against them in a specific case is compared to the corresponding tendency in low-reputation states, the difference is not statistically significant. ${ }^{103}$ Similarly, when the tendency of high-reputation states to respond to all reports filed against them in a specific case is compared to the corresponding tendency of low-reputation states, the difference is also not statistically significant. ${ }^{104}$ The data do not suggest any reason to believe that NGOs focus their efforts on high-reputation states because they are more likely to reply to their accusations than are lowreputation states.

2. Willingness to Cooperate with the Committee of Ministers

States may differ in their willingness to cooperate with the CM by filing action plans - a plan for how they are about to comply with the judgments issued against them - or action reports: a report of the measures already taken to comply. States can demonstrate special willingness to cooperate by filing this plan on time, within six months after a judgment becomes final. ${ }^{105}$ As argued in the last sub-part, differences in states' willingness to file action reports raise the possibility that NGOs may prefer to intervene in cases

102. NGO Report (2013)720.

103. P value of 0.1676 .

104. P value of 0.3781 .

105. Miara \& Prais, supra note 29, at 531. The terms "action plan" and "action report" are used interchangeably here - they both describe documents submitted by states to explain how they are complying or how they will comply with the judgments against them. 
against states that cooperate with the $\mathrm{CM}$ in this way, thereby providing NGOs with a visible impact on state behavior.

Writing an action report and undertaking the necessary work to complete it also provides NGOs access to information that may make filing NGO reports easier. In fact, NGOs often write reports that respond to and criticize claims by states in their action reports. A report filed by the Helsinki Foundation for Human Rights on February 26, 2014 is a good example. ${ }^{106}$ This report is more than twenty pages long, and primarily casts doubts on and critiques claims made by Poland in the action report it filed in response to the Trzaska group of cases ${ }^{107}$ concerning excessive length of pre-trial detentions.

Table 7 displays information about states' tendency to file action reports in cases that led to NGO reports conditioned on the states' reputation:

Table 7: Filing Action Reports Conditioned on States' Reputations

\begin{tabular}{|l|l|l|l|}
\hline \hline Reputation Level & $\begin{array}{l}\text { No Action Report } \\
\text { filed }\end{array}$ & $\begin{array}{l}\text { Action Report Filed } \\
\text { Later Than 6 } \\
\text { Months After Final } \\
\text { Judgment }\end{array}$ & $\begin{array}{l}\text { Action Report Filed } \\
\text { Within 6 Months } \\
\text { From Final } \\
\text { Judgment }\end{array}$ \\
\hline 1 (Disregard) & $0 \%$ & $0 \%$ & $0 \%$ \\
\hline 2 (Disregard) & $0 \%$ & $100.00 \%$ & $0 \%$ \\
\hline 3 (High Reputation) & $16.67 \%$ & $70.00 \%$ & $13.33 \%$ \\
\hline 4 (High Reputation) & $29.03 \%$ & $48.39 \%$ & $22.58 \%$ \\
\hline 5 (Low Reputation) & $29.33 \%$ & $61.33 \%$ & $9.33 \%$ \\
\hline
\end{tabular}

When the tendency of high-reputation states to file action reports is compared to that of low-reputation states, the differences are not statistically significant. ${ }^{108}$ Differences in states' tendency to file action reports on time are not statistically significant either. ${ }^{109}$ Therefore, the data do not suggest that NGOs focus on high-reputation states simply because they are more likely than low-reputation states to cooperate with the CM.

3. Willingness to Comply with Judgments

Another factor that NGOs may take into account is the willingness of states to comply with the ECHR's judgments that garnered NGO attention. Compliance may indicate that a state cares about the reputational sanction attached to its misbehavior and is willing to sustain the costs of compliance to avoid this reputational sanction. Nonetheless, a state may also comply

106. NGO Report (2014)356.

107. See Trzaska v. Poland, App. No. 25792/94, Eur. Ct. H.R. (2000) (unpublished), http://hudoc.ech r.coe.int/eng?i=001-58750.

108. P value of 0.4395 .

109. P value of 0.2026 . 
with a judgment without changing its behavior in other areas. NGOs may still have an incentive to file reports against states that usually comply with ECHR judgments subject to such reports, because this allows NGOs to claim they played a role in facilitating state compliance.

If a state complies fully with an ECHR judgment, the CM will close the case. This is the strongest possible indication of full state compliance. Table 8 presents data on cases that led to NGO reports that were closed by the CM until January 2015.

Table 8: Cases Closed by the Committee of Ministers

\begin{tabular}{|l|l|l|}
\hline \hline $\begin{array}{l}\text { State Average Level of } \\
\text { Reputation }\end{array}$ & $\begin{array}{l}\text { Cases Closed by January } \\
2015\end{array}$ & $\begin{array}{l}\text { Cases Still Pending as of } \\
\text { January 2015 }\end{array}$ \\
\hline 1 (Disregard) & $0 \%$ & $0 \%$ \\
\hline 2 (Disregard) & $0 \%$ & $100.00 \%$ \\
\hline 3 (High Reputation) & $23.33 \%$ & $76.67 \%$ \\
\hline 4 (High Reputation) & $9.68 \%$ & $90.32 \%$ \\
\hline 5 (Low Reputation) & $9.33 \%$ & $90.67 \%$ \\
\hline
\end{tabular}

The difference between the proportion of cases closed in highreputation states and in low-reputation states is not statistically significant. ${ }^{110}$ There is, therefore, no reason to suspect that NGOs focus their attention on high-reputation states only because these states are likely to quickly comply with ECHR judgments that draw NGO attention.

\section{NGO Past Involvement}

Another possible factor affecting the results may be that NGOs were involved in the case at initial stages by filing amicus curiae briefs, and then followed up on the case by filing reports regarding noncompliance. The possibility that NGOs are interested in monitoring compliance in cases they participated in as friends of the court, or even as legal representatives of the applicants, is certainly intuitive; NGOs that already acquainted themselves with the information pertaining to a certain issue - and moreover staked their reputation on their success to change state practice on this issue - are likely to monitor compliance with the judgment. ${ }^{111}$ Furthermore, some NGO officials stressed that it is considered bad practice in the NGO community to get involved in cases that were first litigated by other NGOs without their permission. ${ }^{112}$ Others emphasized that following a case through and making sure the judgment is implemented is part of their holistic strategy of initiating

110. P value of 0.2977 .

111. See Shai Dothan, Luring NGOs to International Courts: A Comment on CLR v. Romania, 75 ZEITSCHRIFT FÜR AUSLÄNDISCHES ÖFFENTLICHES RECHT UND VÖLKERRECHT 635, 643-44 (2015).

112. Skype Interview with Official, Russian Justice Initiative (June 1, 2015). 
social change. ${ }^{113}$ Still others said that if they represented applicants, they view themselves as obligated to ensure that the judgment they received will be implemented as fully as is feasible. This is simply part of the service they provide. ${ }^{114}$

This conjecture is also confirmed by the data: out of the twenty-six cases in the pool of cases that led to NGO reports that had an NGO who submitted an amicus curiae brief, fifteen cases included at least one report by at least one of the NGOs who were involved as a friend of the court. The other eleven cases included reports filed only by other NGOs. Considering the number and diversity of potential NGOs, these figures are revealing.

NGOs often participate in cases informally by sending their lawyers to represent applicants or even funding legal assistance by external lawyers. ${ }^{115}$ However, this type of informal participation is much more difficult to track and to quantify than participation as a friend of the court, which is regularly mentioned in the body of the judgment.

The data suggest that NGO involvement as third parties does not explain the practice of filing more NGO reports against high-reputation states than against low-reputation states. Out of seventy-five cases that concerned low-reputation states, ten (13.33\%) included NGOs as friends of the court. Out of sixty-one cases that concerned high-reputation states, fifteen $(24.59 \%)$ included NGOs as friends of the court. The difference between the propensities of high-reputation states and low-reputation states to attract the involvement of NGOs as amicus curiae is not statistically significant. ${ }^{116}$ The claim that NGO involvement as third parties explains patterns in the filing of NGO reports is therefore not supported by the data.

113. Skype Interview with Lawyer, Minority Rights Group International (June 11, 2015).

114. Phone Conversation with Lawyer, European Human Rights Advocacy Centre (June 25, 2015).

115. See, e.g., P. and S. v. Poland, App. No. 57375/08, Eur. Ct. H.R. (2012), http://hudoc.echr.coe.int/ eng?i=001-114098 [https://perma.cc/3ZMH-3RY6] (where lawyers from the Center for Reproductive Rights assisted with the representation of the applicants). The Center for Reproductive Rights later filed a report concerning this case. See LOVEDAY HODSON, NGOs AND THE STRUGGLE FOR HUMAN RigHTS IN EUROPE 55-56 (2011) (suggesting that a large part of the involvement of NGOs in ECHR proceedings is informal).

Another possibility worth mentioning is that an NGO would serve as an applicant itself. See, e.g., Jehovah's Witnesses of Moscow v. Russia, App. No. 302/02, Eur. Ct. H.R. (2012), http://hudoc.echr.coe.i $\mathrm{nt} / \mathrm{eng}$ ?i=001-99221 [https://perma.cc/WK3C-LPSS] (where the applicant is itself an NGO). In this case, the applicant NGO didn't file a report, but other NGOs did. In contrast, in the case of Genderdoc-M v. Moldova, App. No. 9106/06, Eur. Ct. H.R. (2012), http://hudoc.echr.coe.int/eng?i=001-111394 [https://perma.cc/4HMB-Q84S] the applicant is an NGO who later filed a joint report with another NGO.

116. $\mathrm{P}$ value of 0.1196 . Notice this compares both data on friends of the court that filed reports and data on those that didn't file reports, that is, when only other NGOs filed reports. The reason is that this test assumes that filing the amicus curiae brief by itself generates an incentive for the NGO who filed the brief to file a report later on, as could other forms of intervention that may not be visible from the case. To complete the picture, only seven $(11.48 \%)$ cases in high-reputation states and seven $(9.33 \%)$ cases in 
5. A Concentration of Severe and Important Violations in HighReputation States

Finally, there exists a potential alternative explanation that is largely non-intuitive: maybe there is a greater proportion of cases that involve severe violations or important legal issues concerning high-reputation states than low-reputation states. As Part II shows, NGOs focus their attention on severe and important cases. If high-reputation states commit on average more severe violations or lead to more important cases, maybe this is the reason why they face more NGO reports.

It is unlikely that the cases directed at high-reputation states involve, on average, more severe violations. This possibility can be checked by comparing the proportion of ECHR judgments among the general population finding severe violations in low-reputation states and in high-reputation states. In fact, there are proportionally more cases involving violations of Articles 2, 3, and 13 in low-reputation states, ${ }^{117}$ and these differences are statistically significant. ${ }^{118}$ This is consistent with the simple intuition that low-reputation states are generally responsible for more severe violations. On the other hand, there are proportionally more Article 14 violations in high-reputation states. ${ }^{119}$ This difference is statistically significant as well, ${ }^{120}$ suggesting that high-reputation states may be especially prone to unlawful discrimination between individuals, or at least are more often accused of such practice. ${ }^{121}$

High-reputation states also draw a greater proportion of important cases. $0.97 \%$ of the cases filed against low-reputation states in the general population of cases are classified as Case Reports, and $2.11 \%$ are classified as Importance Level 1 . The corresponding figures for high-reputation states are $4.31 \%$ and $5.09 \%$. When the propensity to generate either Case Reports,

low-reputation states have a report by an NGO who submitted itself an amicus curiae brief. This difference is not statistically significant ( $\mathrm{P}$ value of 0.7796 ). It is also possible that NGOs may be influenced by other NGOs' participation: namely, NGOs may be motivated to file reports by the involvement of other NGOs as friends of the court. All this leads to the hypothesis that the reports against high-reputation states are caused by a greater propensity of NGOs to file amicus briefs vis-à-vis these states. Yet, since no such propensity appears in the data, the hypothesis is rejected.

117. In low-reputation states, $7.16 \%$ of the judgments found Article 2 violations, $17.74 \%$ found Article 3 violations, and $11.09 \%$ found Article 13 violations. In high-reputation states, the respective figures are: $1.86 \%, 25.69 \%$, and $9.16 \%$.

118. P values of less than 0.0001 for Articles 2 and 3, and a $\mathrm{P}$ value of 0.0296 for Article 13 .

119. In low-reputation states, $1.01 \%$ found Article 14 violations. In high-reputation states, the relevant figure is $3.59 \%$.

120. $\mathrm{P}$ value of less than 0.0001

121. Note that for this calculation, judgments in the general population directed against two states that include a violation were counted twice (even if the judgment found a violation was committed only by one state). Because these cases are very rare, this should not affect the result. 
Importance Level 1 cases, or cases of these two categories combined is compared, all these differences are statistically significant. ${ }^{122}$

This raises a question: is it the importance of the cases filed against high-reputation states that explains their greater propensity to attract NGO reports? To answer this question, the importance levels of cases that actually led to NGO reports can be compared. $26.67 \%$ of the cases that led to NGO reports filed against low-reputation states are Case Reports cases and $22.67 \%$ are categorized as Importance Level 1. The figures for high-reputation states are $36.07 \%$ and $14.75 \%$. When comparing the propensity of a case to be categorized at the highest level of importance (Case Reports) or at the two highest levels combined (Case Reports and Level 1), no statistically significant differences appear. ${ }^{123}$ Therefore, while high-reputation states may indeed usually draw more important cases, this difference cannot explain the fact that they are subject to more NGO reports, since cases that led to NGO reports do not significantly differ in their importance between high and low-reputation states.

To complete the picture, it is possible to compare the severity of cases that led to NGO reports in low-reputation states and in high-reputation states. This test can help refute a more distant possibility - although high-reputation states are generally responsible for less severe violations (besides issues of discrimination under Article 14), perhaps they are responsible for more severe violations discussed in cases of a special quality (such as legal importance) that usually draw the attention of NGOs. The only article indicating severity that is more common in high-reputation states is Article 14 , but the difference concerning this article is not statistically significant. ${ }^{124}$ In contrast, the tendency of low-reputation states to generate more violations of Articles 3 and 13 that led to NGO reports is statistically significant at the 0.1 level. ${ }^{125}$ An additional test for a violation's severity is the amount of just satisfaction issued in the case. Comparing the just satisfaction issued in cases that led to NGO reports in low-reputation states and in high-reputation states does not find statistically significant differences. ${ }^{126}$

122. All three comparisons lead to $P$ values of less than 0.0001 .

123. $\mathrm{P}$ values of 0.2663 and 1.0000 , respectively.

124. Of the cases filed against low-reputation states that led to NGO reports, $16.00 \%$ concerned Article 2 violations, $34.67 \%$ concerned Article 3 violations, 26.67\% concerned Article 13 violations, and $10.67 \%$ concerned Article 14 violations. In cases filed against high-reputation states, $9.84 \%$ concerned Article 2 violations, $19.67 \%$ concerned Article 3 violations, $13.11 \%$ concerned Article 13 violations, and $16.39 \%$ concerned Article 14 violations.

125. Article $3-\mathrm{P}$ value of 0.0576 ; Article $13-\mathrm{P}$ value of 0.0580 .

126. In low-reputation states, $16.00 \%$ of the cases that led to NGO reports involved just satisfaction of more than 100,000 Euros, and 50.67\% involved just satisfaction of more than 10,000 Euros. In high- 
The data suggest that judgments discussing severe violations of the kind that is likely to draw NGO reports are not more commonly issued against high-reputation states than against low-reputation states. Perhaps the opposite is correct. It seems only natural to conclude that there are more severe violations committed by low-reputation states that led to NGO reports, although the data are not very strong on this point. If reports against low-reputation states do indeed target more severe violations, the reason may be that low-reputation states simply commit a greater share of the most severe violations in Europe. But it is also possible to interpret this admittedly weak data as further support for the argument that NGOs are more willing to file reports against high-reputation states. This conclusion can be reached because the data suggest that NGOs are willing to extend their shaming efforts even to less severe violations committed by high-reputation states. The human rights standards required from high-reputation states may simply be higher. If high-reputation states commit violations of lesser severity - that would not lead to reports if committed by low-reputation states - they may nevertheless be subject to reports.

\section{Conclusions about the Focus of NGOs on High-Reputation States}

This part presents a systematic way to divide states in Europe into highreputation states and low-reputation states. It shows that NGOs issue more reports per judgment related to judgments involving high-reputation states than related to judgments involving low-reputation states. This suggests that high-reputation states are more vulnerable to reputational sanctions than low-reputation states. Several alternative explanations for NGOs' tendency to focus on high-reputation states specifically within the DEJ procedure were examined, but none of these explanations finds support in the data.

\section{WHAT DO NGOS REALLY WANT?}

Parts II and III present certain patterns in the issues and the states on which NGOs focus their shaming efforts. These patterns may reveal important insight into the nature of reputational sanctions in international law. They may reveal, for example, when reputational sanctions cause the most damage, and how accurate is the information transmitted by shaming efforts. These insights are the subject of Part V. Before jumping to general insights about reputation, though, the characteristics of the NGOs that published on the DEJ website must be studied. By exposing the incentives of the NGOs involved, it is possible to verify if these incentives, rather than

reputation states, the corresponding figures are $6.56 \%$ and $42.62 \%$. The differences are not statistically significant: more than 100,000 Euros (P value of 0.1117); more than 10,000 Euros (P value of 0.3904). 
the general nature of reputational sanctions, are responsible for the observed patterns of NGO behavior.

\section{A. Separating NGOs According to Size}

As a first take on this problem, it may be helpful to check if NGOs act differently depending on their size. If the core players using the DEJ website are large, well-funded NGOs, maybe they are simply following the interests of their patrons. Could it be that donors from rich democracies support NGOs that focus on their own countries of origin because of the donors' liberal commitments? If this bias is strong enough, the greater wealth and larger human rights community in high-reputation states may very well explain the focus of NGOs on this type of states.

Yet the data shows that big NGOs are actually responsible for a very small part of the reports filed on the DEJ website. The world-wide NGO Human Rights Watch is only responsible for addressing a single case. Even the global mega-organization Amnesty International was involved in filing reports in only seven cases. Liberty is an NGO focused on human rights in the United Kingdom, but at the same time, some consider it to be the most frequent litigator before the ECHR. ${ }^{127}$ Yet despite its involvement at the trial phase, this major NGO was involved in reports addressing only one case. ${ }^{128}$ No less telling is the fact that in all the cases targeted by reports from these three major players, other NGOs also filed the same or other reports. Furthermore, even this miniscule sample of reports by the big three organizations is evenly divided between four cases concerning highreputation states and four cases concerning low-reputation states. ${ }^{129}$

This suggests that the community of NGOs is actually incredibly diverse. More than two hundred organizations, big and small, domestic, European, and global in focus submitted reports and took part in the efforts to shame states for noncompliance. In this open and teeming community, fears of a centralized strategy orchestrated by a few tycoons or stemming from the wealth inequalities between European states can be alleviated.

127. See HoDSON, supra note 115 , at 107.

128. It may be interesting to theorize about the reasons large organizations filed so few reports. Perhaps these reports are used only by organizations that cannot make an impact in another way. Perhaps the large number of workers at large NGOs, each with her own specialty, prevents one person for having the set of skills necessary for filing a report: a familiarity both with the specific subject matter and the machinery of the CM.

129. Amnesty International even signed a report for the only case in the sample from a "reputation level 2" state, which is excluded from the analysis in Part III. 


\section{B. The Incentives of NGOs}

Alleviated perhaps, but not eliminated. Several conversations with NGO activists revealed that foundations that fund NGOs have developed a strategy to bend these organizations to their will. More and more foundations would earmark certain funds for certain purposes such as aiding a specific right or a specific region. ${ }^{130}$ Small NGOs need money for things as trivial as office supplies and paying salaries. They are forced to take the directives of these foundations seriously. ${ }^{131}$ If powerful foundations use this technique efficiently, they could operate indirectly through countless tentacles and sway the general attention of civil society in a specific direction.

Some foundations openly champion this strategy of operating from multiple NGOs simultaneously. The European Program for Integration and Migration ("EPIM") even takes centralization up a level. It is a collaboration of thirteen European foundations that work together to strengthen civil society organizations. EPIM does not only give grants; it also organizes workshops and funds professional training for NGOs to build their knowledge and capacities. Furthermore, it supports networking between NGOs to facilitate mutual learning and collaboration. ${ }^{132}$ Another major network of NGOs, created in 1994, is the Human Rights House Network. It unites ninety NGOs in Europe and Africa that cooperate with one another in an effort to improve their effectiveness. ${ }^{133}$ Though the different NGOs are independent, the secretariat of this large network, based in Oslo, can doubtlessly exert substantial influence on the actions of civil society across Europe and beyond. Some wealthy countries, especially Scandinavian countries, do not operate solely through foundations. Rather, they directly fund NGOs supporting causes they care about. ${ }^{134}$

To address the possibility that centralized power lies behind the observed patterns in NGO behavior, it is vital to talk to NGO officials and see what it is they really aim at achieving, taking their commitments and constraints into account.

This much seems clear from the interviews: high-reputation states cannot expect an especially lenient treatment because of their status. One

130. Foundations differ in how strictly they monitor spending, but often reports of spending must be quite accurate. Skype conversation with NGO Lawyer 10 (June 12, 2015).

131. Interview with NGO Lawyer 1 (Apr. 14, 2015).

132. See About EPIM, EUROPEAN PROGRAMmE FOR IMmigRATION AND MigRation, http://www.ep im.info/ [https://perma.cc/LZ7D-WY9X].

133. See About the Human Rights House Network, Human Rights House NeTwORK, http://humanrightshouse.org/noop/page.php?p=HRHN/index.html\&d=1 [https://perma.cc/BM5W-SRS $\mathrm{S}]$.

134. Skype interview with Lawyer, Minority Rights Group International (June 11, 2015). 
NGO lawyer suggested that if a violation was proven against a state, then, by definition, it behaves imperfectly and should not be granted any favors by NGOs. ${ }^{135}$ Another NGO lawyer stressed repeatedly that even the most highly acclaimed democracies commit violations and crimes. ${ }^{136}$ Interviewees focused on the need to make a difference in the world. This suggests that the most energy should not be dedicated to the best behaving states-they behave well anyway - nor to the worst behaving states - they are unlikely to change their behavior in any case - but instead to states located somewhere in the middle. That is, states that commit violations, but could be pressured to correct them. ${ }^{137}$

NGO activists who focus on high-reputation states stress that their government is often receptive to criticism. For example, an official at Association Nationale d'Assistance aux Frontières pour les Étrangers ("ANAFE") — a French NGO assisting foreigners at the border — said that lawyers and officials in France care about ECHR judgments and change their practices to avoid future violations. ANAFE built a reputation as an expert on migration, and French bureaucrats learn from it and communicate with it directly. For ANAFE, NGO reports like those studied in this Article, serve as a complementary method to communicate indirectly with French officials. This method carries beneficial results on the ground as state officials learn from the reports and change their behavior. ${ }^{138}$

This stands in sharp contrast to the conditions NGOs face in lowreputation states. A Romanian NGO lawyer confessed that he did not believe NGO reports have any direct impact on Romania, which replies to their reports in an utterly unhelpful manner. Instead, the NGO's strategy is to exert pressure on the CM in the hope that the CM would, in turn, pressure the Romanian government. ${ }^{139}$ In Russia, NGOs singled out the CM machinery as the only effective way to get information from their government. Russian officials do not communicate with NGOs. Consequently, activists can only get the data they need to pursue further legal action by acting indirectly through the Strasbourg system. ${ }^{140}$ While in other countries, such as Lithuania, NGOs are in direct contact with their government delegations to the CM, ${ }^{141}$ Russian NGO lawyers speak to delegations of other countries at

135. Interview with NGO Lawyer 1 (Apr. 14, 2015).

136. Skype interview with NGO Lawyer 11 (July 3, 2015).

137. Interview with NGO Lawyer 1 (Apr. 14, 2015).

138. Telephone Interview with Official, ANAFE (May 27, 2015).

139. Skype Interview with Romanian NGO Lawyer 9 (May 25, 2015).

140. Skype Interview with Official, Russian Justice Initiative (June 1, 2015).

141. Skype Interview with NGO Activist 2 (May 2, 2015). 
the CM to urge them to criticize Russia in the CM's closed meetings. Such efforts may have led to interim resolutions against Russia. ${ }^{142}$

So far, it seems that NGOs' focus on high-reputation states is justified by the willingness of these states to change their practices due to criticism, which, in turn, directly relates to the value they put on their reputation. But the picture is more complex than that. In low-reputation states, NGOs are often subject to effective national measures meant to suppress their activity. NGOs in Russia - at least those which receive money from abroad or engage in actions such as advocacy that involve foreigners - are forced by law to declare themselves as "foreign agents" in all their official documents. This designation carries a powerful stigma, something akin to calling yourself a spy. Furthermore, NGOs are subject to daily acts of harassment by countless forms of bureaucratic hurdles. They have to submit numerous forms and be subject to frequent inspection. Add to that a public sentiment that views human rights activity as a form of foreign intervention and as a reason for Russia's financial problems and you have a potential reason for the relative paucity of NGO actions vis-à-vis Russia. ${ }^{143}$

Russia and other states coded here as having low reputations are not alone in their actions against NGO activity. In Azerbaijan, civil society activists are subject to false arrests, to unjustified searches, and even to violence. Furthermore, the government funds so-called GovernmentOrganized Non-Governmental Organizations ("GONGOs") governmentally controlled organizations built and funded for the sole purpose of infiltrating and corrupting the human rights community. ${ }^{144}$ In other post-communist countries, such as Serbia, there is simply no culture of philanthropic investment in fighting for the public interest. ${ }^{145}$ This is a striking difference from countries such as the Netherlands where, with a population of less than 17 million, Amnesty International alone boasts 255,000 members and over 560,000 volunteers. ${ }^{146}$ Cultural differences and differences in government practice may certainly affect the results found in this Article. Furthermore, the procedure investigated here is relatively new

142. Skype Interview with Official, Russian Justice Initiative (June 1, 2015).

143. Skype Interview with Russian NGO Activist 4 (May 15, 2015). Another NGO official admitted that Russian counter-measures proved effective in leading some Russian NGOs to keep a low profile in the media. Skype Interview with Official, Russian Justice Initiative (June 1, 2015).

144. In Azerbaijan as the Last Remnants of Democracy are Being Destroyed, Some Watch in Silence), MEYDANTV (Oct. 29, 2014) http://www.meydan.tv/en/site/society/3532/In-Azerbaijan-asthe-last-remnants-of-democracy-are-being-destroyed-some-watch-in-silence-(part-2—\%E2\%80\%9CG ONGO\%E2\%80\%9Dids).htm [https://perma.cc/38QT-B3TW].

145. Skype Interview with NGO Lawyer 3 (May 4, 2015).

146. Amnesty International the Netherlands, AMNESTY INTERNATIONAL, https://www.amnesty.nl/en glish [https://perma.cc/R6V2-B4Y4]. 
and many NGOs in low-reputation states may simply be unaware of it. ${ }^{147}$ This, however, may also be true for NGOs in high-reputation states. ${ }^{148}$

Despite these caveats, one cannot ignore the fact that there are still numerous NGOs that do target low-reputation states. Many of them, in fact, are based in other countries and collaborate with local organizations. To understand NGO activity, one must consider not only the organizations' constraints, but also the goals that NGOs are trying, often successfully, to achieve. NGO activists stress that they are committed to making a social change. ${ }^{149}$ They insist that they care about actual results, not about the reputation of their own institution. ${ }^{150}$ If others can do the work better, so they say, they would let them take the credit for it. ${ }^{151}$ This attitude explains why NGOs try to cooperate with as many other NGOs as possible in pursuit of a common cause. ${ }^{152}$

But this may be an overly complacent view. NGOs are not just trying to make the world better by any means possible. First, many NGOs have a specific mandate set in advance. For example, the Lithuanian Gay League fights for equality regardless of sexual orientation in Lithuania, not for other worthy causes or for rights in other countries. ${ }^{153}$ Second, NGOs try to prevent an overlap with other organizations and to do things others are not doing. ${ }^{154}$ Most importantly, NGOs compete for a limited amount of funds from a limited number of grants and foundations. This is a recipe for jealousy and competition. Some activists voiced resentment toward bigger NGOs that win large grants by investing the money they receive in internal administration and leaving the actual work to smaller NGOs which struggle for survival. ${ }^{155}$ Others insist that NGOs mark their territory and get upset when others intervene - for example, by filing reports in cases they initiated. ${ }^{156}$

None of this detracts from the fruitful cooperation that does exist between NGOs. NGO activists help each other to form connections and to collect information. ${ }^{157}$ They meet one another in conferences ${ }^{158}$ and in joint

147. Skype Interview with Russian NGO Activist 4 (May 15, 2015).

148. Skype Interview with Lawyer, Minority Rights Group International (June 11, 2015).

149. Skype Interview with Lawyer, Minority Rights Group International (June 11, 2015).

150. Skype Interview with NGO Activist 2 (May 2, 2015).

151. Interview with NGO Lawyer 1 (Apr. 14, 2015).

152. Skype Interview with NGO Activist 8 (May 20, 2015).

153. See Mission and Goals, ASSOCIATION LiTHUANIAN GAY LEAGUE, http://www.lgl.lt/en/?page_id $=116[$ https://perma.cc/8GPU-ZFHM] .

154. Skype Interview with NGO Lawyer 3 (May 4, 2015).

155. Skype Interview with NGO Lawyer 3 (May 4, 2015).

156. Skype Interview with Official, Russian Justice Initiative (June 1, 2015).

157. Skype Interview with NGO Activist 2 (May 2, 2015).

158. Skype Interview with NGO Activist 8 (May 20, 2015). 
training sessions where they engage with other people they could turn to for advice in the future. ${ }^{159}$ Language barriers sometimes make NGO collaboration difficult, so do differences in institutional culture, such as the unequal time it takes to reply to an email. ${ }^{160}$ NGOs struggle to collaborate despite these challenges. At the same time, NGOs engage in other forms of collaboration. While there are NGOs that simply send reports as letters to the $\mathrm{CM},{ }^{161}$ others have a fruitful cooperation with its members. ${ }^{162}$ While some NGOs do not use the media because they deal with less salient issues, ${ }^{163}$ others actively try to shape public policy by using the media. ${ }^{164}$

To conclude, despite facing different challenges, NGOs in highreputation states and in low-reputation states are both adapting their strategies to the realities they are facing. Generally speaking, NGOs are committed to social change, even if some of their policies are mediated by self-interest. Criticizing high-reputation states is likely to be more successful because state officials care about the reputation of their country and are willing to work hard to preserve it. Consequently, a focus on high-reputation states is only to be expected. Some low-reputation states care so little about their reputation that they are even willing to launch a public battle against the human rights community, despite the inevitable reputational costs that such a policy entails. ${ }^{165}$

\section{IMPROVING REPUTATIONAL ASSESSMENTS}

The analysis of states' reputation so far collects data on the behavior of states and on the shaming efforts against them. In contrast, states' reputation is actually a belief of the international community about the states' past behavior - their failure to comply with ECHR judgments - that can help predict their future behavior: their propensity to fulfill their international obligations. ${ }^{166}$ This belief is plagued by uncertainty on two accounts: information about the nature of the states' actions is ambiguous and the

159. Skype Interview with NGO Activist 5 (May 15, 2015).

160. Skype Interview with Russian NGO Activist 4 (May 15, 2015).

161. Skype Interview with Romanian NGO Lawyer 9 (May 25, 2015).

162. Skype Interview with NGO Activist 2 (May 2, 2015).

163. Telephone Interview with Official, ANAFE (May 27, 2015).

164. Skype Interview with Lawyer, Minority Rights Group International (June 11, 2015).

165. See Miriam Elder, Russia Raids Human Rights Groups in Crackdown on 'Foreign Agents', THE GUARDIAN (Mar. 27, 2013), http://www.theguardian.com/world/2013/mar/27/russia-raids-human-rightscrackdown [https://perma.cc/J2FZ-TGH2] (citing foreign officials' and NGOs' criticism of Russian policies in this regard).

166. See Gregory D. Miller, Hypotheses on Reputation: Alliance Choices and the Shadow of the Past, 12 SECURITY STUDIES 40, 42 (2003) (using a similar definition of reputation as: “. . . a judgment about an actor's past behavior that is used to predict future behavior"). 
judgments formed by spectators of the states' actions may be biased. This Article addresses these problems in turn.

\section{A. Imperfect Information Makes Every Deed Count}

NGO reports are primarily a method of exposing information about states' compliance with ECHR judgments. But even strong and committed NGOs do not have access to all of the necessary facts. They must form impressions based on partial and imperfect information, and these impressions may certainly be wrong.

Furthermore, even if the facts of the matter are clear, they may still be subject to interpretation. The ECHR often issues judgments that require several types of measures: paying compensation for damages, undertaking specific measures to redress the violation, and making general legal changes to amend the root cause of the violation. ${ }^{167}$ If a state complies with some of these dictates, but not with others, it is unclear whether it should be branded as failing to comply with its obligations.

The problems of dealing with partial compliance are demonstrated in a report filed against the government of Azerbaijan by the Media Rights Institute, a NGO based in that country. The report concerned how Azerbaijan complied with judgments that found it violated the right to freedom of expression guaranteed by the Convention when it imprisoned certain journalists for defamation. ${ }^{168}$ The NGO noted that the journalists whose rights were violated received full compensation and were released from prison. Yet at the same time it stressed that these journalists were pardoned and not retried, and that the legal changes attempted by Azerbaijan did not suffice to prevent future violations. ${ }^{169}$ Calibrating the level of Azerbaijan's compliance is a complex matter. It requires not only surveying the facts, but also making difficult value judgments.

Another problem with detecting compliance is how to treat delay in a state's actions. ${ }^{170}$ When states are required to undertake structural changes to their legal system, they never comply instantaneously, nor are they expected to. But what constitutes a reasonable delay? After how long can observers deduce a state is truly unwilling to comply with a judgment? And

167. Scozzari and Giunta v. Italy, 2000-VIII Eur. Ct. H.R. 471, 528.

168. DH-DD(2013)971, Communication from a NGO (Media Rights Institute) (12/09/2013) in the cases of Mahmudov and Agazade and Fatullayev against Azerbaijan (Apps. No. 35877/04 and 40984/08) (2013).

169. Id.

170. See Eric A. Posner \& John C. Yoo, Judicial Independence in International Tribunals, 93 CAL. L. REV. 1, 28 (2005). 
if a state complies after this point in time, what does this say about its reputation ${ }^{171}$

The uncertainty shrouding states' reputations runs even deeper than that. States build their reputation by signaling not only to NGOs but primarily to other states that they are willing to sustain certain costs in order to maintain their reputation for the future. No one expects states to suffer limitless costs. Even a state that cares deeply about its reputation will only comply if the reputational sanction it will suffer by noncompliance is greater than the costs entailed by compliance. The problem is that there is no way for NGOs to observe the true costs of compliance for the state.

The actual costs of compliance are unobservable because when the court requires complex legal measures, undertaking them can lead to all sorts of consequences. If the state is required to release prisoners, for example, compliance may damage deterrence of certain crimes. It may also lead to public opposition to the government from certain groups in society. If a government is required to change its laws, doing so may jeopardize its policy goals in a variety of ways. Furthermore, compliance with a judgment has an expressive function, which creates its own costs. States may perceive compliance as an acknowledgment of guilt that has reputational consequences. In contrast, they may view compliance as exonerating the state from guilt for the initial violation by paying the price that legitimizes its actions. ${ }^{172}$ Finally, state compliance sets a precedent for its behavior, a precedent it may be pressured to follow in the future at its own cost. ${ }^{173}$

If the costs of the state were observable, only the most demanding judgment a state complied with would count as a signal, because it indicates the limit of what the state is willing to pay to preserve its reputation. Compliance with less demanding judgments would signal nothing new about the state's reputation. ${ }^{174}$ In contrast, because real costs of compliance are unobservable, there is always a possibility that a certain judgment costs more

171. If a state complies after a long time, it may have already endured severe reputational damage only part of which can be rebuilt by noncompliance. The state's willingness to shoulder the costs of compliance for this partial rehabilitation of its reputation indicate that it views the reputational sanction as particularly large and should therefore signal its high reputation. At the same time, the state's reluctance to comply earlier on should serve as a negative reputational signal. Moreover, if as time passed conditions changed and made compliance less costly, as is often the case, the belated compliance should count as a weaker signal of the state's good reputation.

172. Cf. Uri Gneezy \& Aldo Rustichini, A Fine is a Price, 29 J. Legal STUd. 1, 13-14 (2000) (describing how people sometimes view fines as a price the payment of which erases all guilt for the initial transgression).

173. See DOTHAN, supra note 95 , at 30-32.

174. See ANDrew GuZMAn, How InTERnAtional LAw WORKS - A RATIONAL CHOICE THEORY 83 (2008) (arguing that if a state behaves according to prior expectations, this may affirm its reputation but would not change it). 
than the state was previously willing to pay. As a result, every action of compliance sends a signal that increases the state's reputation. But although the international community cannot know for sure how demanding compliance would turn out to be, it certainly has assessments about the costs of compliance. Compliance with a judgment that appears more demanding, even if its compliance costs cannot be perfectly calibrated, would lead to a much higher reputational boost than a judgment that appears to require only cheaper actions. ${ }^{175}$

The reputation of states is therefore flexible. A state's actions-or, more accurately, the stipulations of actors in the international community about these actions - constantly change the state's reputation for better or for worse. It seems reasonable to assume that as these stipulations multiply, the state's reputation would lead to increasingly better predictions of the state's conduct. Mistakes and exaggerations by different actors about the state's past conduct would offset one another, and the true character of the state would gradually be revealed.

In a community composed of states and their leaders, an additional mechanism may improve the assessments of states' reputation even further: states will acquire a reputation for reliability in their accusations against other states. As the network between the states develops to include strong multiple ties, states will learn which states they can trust to tell the truth about the conduct of other states. As states learn to ascribe differing degrees of credibility to stipulations on other states, their assessments of the reputations of these states will constantly improve. ${ }^{176}$

\section{B. Opening the Shaming Community to Prevent Echo}

The analysis so far describes a network that sociologists define as complying with the so-called "bandwidth hypothesis": the network resembles a pipe through which information is transmitted; the denser the

175. See DothAN, supra note 95, at 19-20 (suggesting that although states gain a lot of reputational capital from compliance with a demanding judgment, this judgment usually indicates that the state initially committed a severe violation, which could damage its reputation. This Article, however, is focused only on the conditions prevailing after the violation already occurred and the judgment against the state was issued. At this point in time, state's conduct can rebuild its reputation by compliance or damage it by noncompliance).

176. Reliability is an asset that can serve states in the long term, but it involves costs in the short term, such as investing in data gathering and facing up to difficult and unpopular truths. Therefore, states with low discount rates - which are also likely to have high reputations for compliance with international law, as argued in Part VI-are going to be considered generally more reliable. The quest for reliability and the quest for compliance reputation intertwine; as states pursue both, they have an incentive to lead international opinion on other states' reputations in the right direction. 
network, the wider the pipe and the more accurate information becomes. ${ }^{177}$ But sociologists also speak about a competing hypothesis, a hypothesis that unfortunately may more accurately represent the tension existing between states in the Council of Europe. It is called the "echo hypothesis" and it argues that information flow within a dense network is not enhanced but rather corrupted. As actors report the actions of others, they do not say the whole truth and nothing but the truth. Instead, they are biased by their prior dispositions as well as the dispositions of the actors with which they interact. ${ }^{178}$ For example, states may be predisposed to think of states with low-reputations as bad actors. Therefore, when they describe their actions, they will paint them in negative colors. These biased reports will then be echoed by other predisposed states, and the reputations of the accused states will plummet. In this example, in contrast with the data uncovered in this Article about the activity of NGOs, high-reputation states stand to gain from the echo effect because reports about their behavior will usually be positive and drive their reputation upwards.

Sociologists run complex tests on networks to determine whether they comply with the echo hypothesis or the bandwidth hypothesis. Devising such tests for the multifaceted diplomatic interactions of states seems nearly impossible. But there is another, more sinister factor that creates a real danger for an echo effect in the Council of Europe. This factor is the fact that states which accuse other states may suffer painful political repercussions. Sadly, states are not only committed to the protection of human rights within and outside their borders. When a state critiques another state, the ties between the two are almost universally damaged. States that want to maintain their friendship with the accused state are also likely to shun the accuser. States may also use accusations to attack their enemies, contributing their share to the corruption of the system of reputation.

The Council of Europe is a close-knit community. In such a community, formal accusations are likely to be rare, because no state wants to damage its international ties. ${ }^{179}$ After all, such a process was already attempted: states can bring cases against other states in the ECHR system according to the Convention. But this process led to very few cases, many of which were

177. See Ronald S. Burt, Brokerage and Closure: An Introduction to Social Capital 167-68 (2005).

178. See id.

179. Robert C. Ellickson, Order Without Law: How Neighbors Settle Disputes 60-61 (1991) (describing a similar close-knit community of farmers in the Shasta County where close ties usually prevent farmers from bringing each other to court). 
plainly political pay-backs, ${ }^{180}$ suggesting that powerful states or states with apparently high-reputations may not be subject to any shaming efforts by other states even if they commit human rights violations.

In contrast, powerless and low-reputations states may be subject to repeated accusations, some of which will likely be false or exaggerated. Accusations against such states can start from purely egotistical motives, as a way for states to distance themselves from the accused state and to curry favor with its adversaries. Once accusations start, they may echo and multiply. As states share information about the accused state, they reinforce each other's predispositions and their views are amplified. The result of this process is that when states interact with each other in a closed system, the reputations of states will be pushed to extremes: either very low or very high reputation, depending on what can be a relatively arbitrary starting point.

A different way to frame this problem is to recognize the potential for a so-called "cascade" of views. Cascades occur when members of a group change their opinions by following others. Reputational cascades occur when group members are pressured to follow each other to avoid reputational loss. Informational cascades occur when group members try to learn from each other's decisions to improve their own policies. ${ }^{181}$ Both types of cascades may materialize here: states may feel a reputational pressure to conform to the underlying beliefs about the conduct of other states, and they may also use information provided by other states to make their own opinion. As states start to follow other states, which in turn followed other states, they may be driven further and further away from what an unbiased and independent judgment would reveal. An arbitrary or malicious accusation may be endlessly repeated and destroy a state's reputation beyond repair.

Another distortion that can occur when states deliberate among themselves over the actions of other states results from the limited pool of arguments - such as specific or general accusations - available within the group of deliberating states. If states are only exposed to a skewed pool of assessments regarding a certain state - which, for example, views that state as a bad actor - the process of deliberation will push the assessments of that state to greater and greater extremes. ${ }^{182}$

180. See supra notes 13-14; see also Scott Leckie, The Inter-State Complaint Procedure in International Human Rights Law: Hopeful Prospects or Wishful Thinking?, 10 HUM. RTS. Q. 249, 254 (1988).

181. See Eric Posner \& Cass Sunstein, The Law of Other States, 59 StAn. L. Rev. 131, 161-63 (2006); Cass R. Sunstein, Deliberative Trouble? Why Groups Go to Extremes, 110 YALE L.J. 71, 78 (2000); see also generally CASS. R. SUNSTEIN \& REID HASTIE, WISER: GETTING BEYOND GROUPTHINK TO MAKE GROUPS SMARTER (2015).

182. See Sunstein, supra note 181 , at 89-90. 
These potential distortions in the formation of states' reputation suggest that leaving it to the states to control the information on the conduct of other states may not be a good idea. To depoliticize this system, the community should be expanded to actors that have less to lose from saying the truth. This is where NGOs enter the picture. NGOs are not as vulnerable to revenge by accused states. They do not have global financial and security interests that can be easily jeopardized. If many NGOs submit reports about a state, they are unlikely to be systematically biased by political alliances. They do not have old scores to settle by false or exaggerated accusations, and they have less to gain by keeping quiet in the face of injustice. If NGOs have dispositions, they are less entrenched and less uniform than those of states and are therefore less likely to reverberate and echo. The inevitable inaccuracies in NGO reports are likely to balance themselves out and lead to stable and fair reputations.

Furthermore, because NGOs are so diverse in their views and their interests, they are likely to present assessments that are less uniform than the ones of the states. This could prevent the exclusion of certain views or arguments from the agenda and minimize the chances of polarizing views by deliberation among actors with similar assessments. Unlike states, NGOs are not part of an exclusive club, and the social ties between them are far less pronounced than between states. Experimental evidence suggests that groups that do not share a common identity are less likely to go to extremes than more cohesive groups, because they can foster divergent arguments and contain less social pressure to conform. ${ }^{183}$

NGOs possess another significant advantage: their purpose as an institution defines a precise role for them. They are expected to criticize states for human rights violations, unlike state representatives that have to maneuver between a series of diplomatic challenges. Many NGOs focus specifically on certain states, on certain types of violations, or quite often on certain violations within certain states. This means that NGOs have narrowly defined roles. Narrowly defined roles, known to the participants in the

183. Id . at 90-92. One way to think about this problem is through so called "threshold models." Imagine that every member of the group has a certain threshold - a number of accusations she must hear from others before she issues an accusation of her own. The number of accusers one needs to hear plausibly depends on the relationship with these individuals. Specifically, the influence of people one is closely connected to is probably much greater than the influence of strangers. This suggests that in groups where people are closely connected to one another thresholds are more likely to be crossed and false rumors would spread more easily. See Mark Granovetter, Threshold Models of Collective Behavior, 83 AMER. J. SOC. 1420, 1423, 1429 (1978). The implication is that the group of state representatives who are closely connected to one another are more likely to form strings of false accusations than NGOs who are not so densely connected. 
dialogue, have been shown in experiments to improve the dissemination of information within groups. ${ }^{184}$

These insights from social science again suggest that opening the arena for the meaningful deliberation of NGOs can prevent the views on states' reputations from polarizing in a way that is deceptive and misleading.

Admittedly, NGOs have their own sinister incentives, but some of them work in favor, not against, the system of reputation. NGOs thrive on publicity. They need publicity to change the world, and most of them need publicity to raise funds and survive. ${ }^{185}$ There is nothing that helps get publicity more than saucy gossip, and saucy gossip is usually counterintuitive. ${ }^{186}$ If an NGO can tarnish an otherwise flawless reputation, it is guaranteed to make headlines. This is consistent with this Article's finding that NGOs focus their attention on high-reputation states, making reputation so difficult to accumulate and turning it-in the manner discussed in Part VI-into a credible signal on states' future actions.

NGOs need publicity to catch the attention of donors, but to get them to open their wallets they need to win their sympathy as well. This raises the specter of NGOs that cater to the interest of powerful players: rich tycoons or, more commonly, governments. These corrupted NGOs - that some refer to as GONGOs ${ }^{187}$ - can sometimes be even more dangerous than governments acting in the open. They allow governments to throw mud with impunity, hiding behind the anonymity provided by cheaply maintained organizations. If such accusations become the norm, the high hopes of transparency generated by NGO involvement will soon be eclipsed by a system of veiled accusations that no state is accountable for. ${ }^{188}$

184. See SUNSTEIN \& HASTIE, supra note 181, at 111-12.

185. See Dothan, supra note 111. The constant struggle for publicity may affect the issues NGOs focus on. See James Ron et al., Transnational Informational Politics: NGO Human Right Reporting, 1986-2000, 49 INT'L STUD. Q. 557, 573 (2005) (suggesting that Amnesty International selected the countries it reported on not only due to human rights conditions, but also due to so-called "information politics." It focused on powerful countries and on countries exposed to media coverage, among other factors, to attract public attention and potential funds).

186. See BURT, supra note 177 , at 110 .

187. See Mauro Palma, The Possible Contribution of International Civil Society to the Protection of Human Rights, in REALIZING UTOPIA - THE FutURE OF INTERNATIONAL LAW 76, 81 (Antonio Cassese ed., 2012).

188. This raises memories of the terrible Lion's Mouth where innocent Venetians were daily accused by cowardly invisible enemies. See generally MARK TWAIN, THE INNOCENTS ABROAD (1869) (describing the Lion's Mouth: a hole in the wall used in Venice when it was ruled by the Patricians to slip notes accusing people anonymously of plotting against the government. Many innocents were accused by their enemies and tried in secret by masked unnamed judges that composed the Council of Three. Chances to escape a death sentence were slim). 
This is a danger that cannot be ignored, but should not be exaggerated. Indeed, NGOs are easily constructed, but they must struggle for years to gain a reputation for credibility and truthfulness. NGOs that have achieved such a reputation are unlikely to risk forfeiting it by serving states' interests. NGOs that did not build this reputation will not be believed by the international community.

Furthermore, while the accusations lodged against states may not reveal the true identity of the states that initiated the accusations-raising the possibility that low-reputation states are secretly supporting the accusations of NGOs against high-reputation states - these accusations are not judged in secret. They are judged by public opinion based on a reservoir of reports that is open to all: to contribute, to respond, and to criticize. Opening the arena for other views minimizes the echo effect. It lets accusations compete in the realm of ideas and arguments, where the best reports stand a fair chance of winning. More than anything, Part II of this Article suggests that this marketplace of ideas actually works: NGOs are focusing their attention on severe violations and on issues of real legal importance. The system did not spiral out of control.

\section{CONCLUSION}

The DEJ website compiles information gathered from numerous NGOs about the compliance of states with ECHR judgments. This technological and institutional novelty makes it increasingly easy for states to monitor each other's human rights behavior. It is a new reality that states collectively gain from as it builds reputation into a useful method for predicting state behavior, thus facilitating efficient interactions between states.

The focus on severe and important issues ensures that relevant information about state practice is exposed. The exposure of information ensures that significant violations by the states will not go unnoticed. This means that states that possess high reputations earned them by compliance with their international obligations, making the system of reputation a viable tool for assessing states' behavior. ${ }^{189}$

The focus of NGO attention may reveal which type of state can lose more from reputational sanctions. Presumably, NGOs try to shame states because they want them to change their behavior, or at least to be punished for their bad practices. NGOs would probably not invest resources for nothing. They would focus their attention on states that have a lot to lose

189. See Oona A. Hathaway, Do Human Rights Treaties Make a Difference? 111 YALE L.J. 1935, 2012 (2002) (arguing that the availability of accurate information about states' conduct is crucial, if the participation of states in human rights regimes is to serve as an effective signal). 
from reputational sanctions against them. If that is indeed the case, then the focus of NGOs on high-reputation states indicates that a high-reputation state is harmed more by a similar reputational sanction than would a lowreputation state. That is good news for the international system of reputation.

In fact, this finding supports a key assumption made in the literature on reputation. High-reputation states are often assumed to lose more from reputational sanctions based on the intuition that when they violate international law they act contrary to the prior expectations of the international community and therefore cause a greater shift in these expectations than would a non-compliant low-reputation state. ${ }^{190}$ This, in turn, gives high-reputation states an incentive to undertake costly actions to preserve their reputation, actions that low-reputation states would not take.

If high-reputation states suffer more from reputational sanctions than low-reputation states, this suggests that earning reputational capital involves constantly increasing costs. If earning reputational capital becomes increasingly difficult as a state increases its reputation, only states that are willing to sustain significant costs will possess high reputations. This reputation sets them apart from the other states. In other words, it is a costly signal of their character, and therefore a credible one. ${ }^{191}$

But what are states signaling when they incur the costs necessary to maintain their reputation? A possible answer is that they indicate they care more about their future international standing than they care about avoiding immediate costs. Adherence to international law per se is important to other states. But it is the willingness to incur immediate costs to do so that really makes a difference for the states' reputation. The willingness to sacrifice benefits in the present in the hope of gaining more in the future is often termed "low discount rate." 192 States with a low discount rate will be justly

190. See Oona A. Hathaway, Between Power and Principle: An Integrated Theory of International Law, 72 U. CHI. L. REV. 469, 510 (2005); GUZMAN, supra note 174, at 83; DOTHAN, supra note 95, at 13.

191. See Michael Spence, Market Signaling: Informational Transfer in HiRing and RELATED SCREENING PROCESSES 16-20 (1974) (developing the theory of signaling to counter situations of asymmetric information); AMOTZ \& AVISHAG ZAHAVI, THE HANDICAP PRINCIPLE - A Missing PIECE OF DARWIN's PUZZLE XIV (1997) (studying a similar system of signals developed by evolution in the animal kingdom. Male peacocks, for example, grow big and cumbersome tails that signal to the females they are able to escape from predators even despite the tail's weight); see generally Michael Spence, Job Market Signaling, 87 Q. J. ECON. 355 (1973).

192. See generally Daniel A. Farber, Rights as Signals, 31 J. LEGAL STUD. 83 (2002) (explaining how states that enforce human rights protections signal their low discount rate); David H. Moore, $A$ Signaling Theory of Human Rights Compliance, 97 Nw. U. L. REV. 879 (2003) (explaining how states that comply with international human rights obligations signal their low discount rate); ERIC A. POSNER, LAW AND SOCIAL NORMS 116 (2000) (explaining how everyday behaviors, such as taking the effort to display the national flag, can signal the low discount rate of individuals). 
perceived as states that are unlikely to break their commitments in pursuit of quick gains. Such states are considered good treaty partners and consequently get better deals in international negotiations. These highreputation states are therefore compensated for their efforts to maintain international law, but only in future transactions. It is the readiness to sacrifice the present for the future that sets high-reputation states apart from low-reputation states. ${ }^{193}$ States that are concerned about the future can be justly perceived as good collaborators that will stay true to their word despite occasional temptations to breach their obligations.

States that were caught violating human rights by the ECHR may lose reputation as a result of shaming by NGOs. But they also gain a significant advantage - they are able to respond to accusations against them and, most importantly, they can rebuild their reputation by complying with judgments to the satisfaction of the CM. A structured process to shape reputation is not important just for states that conduct themselves perfectly. It also creates a workable method of repentance-allowing states to regain reputation by changing their behavior. ${ }^{194}$

193. See GuZMAN, supra note 174 , at 35 . Yet, reputation is not always a prefect tool to predict behavior. See George W. Downs \& Michael A. Jones, Reputation, Compliance and Development, in THE IMPACT OF INTERNATIONAL LAW ON INTERNATIONAL COOPERATION - THEORETICAL PERSPECTIVES 117, 118 (Eyal Benvenisti \& Moshe Hirsch eds., 2004) (arguing that it is possible to predict the behavior of states based on their reputation only in connection with agreements that are subject to similar costs of compliance and that are valued the same or less by the states); Rachel Brewster, Unpacking the State's Reputation, 50 HARV. INT'L L.J. 231, 249 (2009); Rachel Brewster, The Limits of Reputation on Compliance, 1 INT'L THEORY 323, 326, 328 (2009) (voicing the concern that governments have a short life span and will therefore not consider the long-term repercussions of their actions on their state's reputation).

194. See Lisa Bernstein, Opting Out of The Legal System: Extralegal Contractual Relations In The Diamond Industry, 21 J. LEGAL STUD. 115, 126 (1992) (highlighting the importance of an agreed upon penalty to limit the reputational damage caused by a breach). 